Stress, Physical Activity, and Resilience Resources: Tests of Direct and Moderation Effects in Young Adults

*Robin L. J. Lines ${ }^{1}$, Kagan J. Ducker ${ }^{1}$, Nikos Ntoumanis ${ }^{2}$, Cecilie Thøgersen-Ntoumani², David Fletcher ${ }^{3}$, Sarah McGarry ${ }^{4}$, and Daniel F. Gucciardi ${ }^{1}$

${ }^{1}$ School of Physiotherapy and Exercise Science, Curtin University ${ }^{2}$ School of Psychology, Curtin University

${ }^{3}$ School of Sport, Exercise and Health Sciences, Loughborough University ${ }^{4}$ School of Occupational Therapy and Social Work, Curtin University

Author Notes

Robin Lines was supported by a Faculty of Health Sciences International Research Scholarship. Daniel Gucciardi was supported by a Curtin Research Fellowship.

*Address correspondence to Robin Lines, School of Physiotherapy and Exercise Science, Curtin University, GPO Box U1987, Western Australia, 6845. Phone: +61 89266 3653. Email: robin.lines@postgrad.curtin.edu.au

Manuscript accepted for publication in Sport, Exercise, and Performance Psychology: September 22 2018 


\begin{abstract}
Stress is an important consideration for understanding why individuals take part in limited or no physical activity (PA). The effects of stress on PA does not hold for everyone, so examinations of possible moderators that protect individuals from the harmful effects of stress are required. Aligned with a resilience framework, individual resources (e.g., hope, self-efficacy) may buffer the maladaptive effects of stress, such that people who have access to these resources in greater quantity may be more "resilient" to the deleterious effects of stress on PA. This study was designed to test this expectation. In total, 140 Australian undergraduate students $\left(70.7 \%\right.$ female, $\left.\mathrm{M}_{\mathrm{age}}=21.68 \pm 4.88\right)$ completed a multi-section survey, and provided a sample for hair cortisol concentration (HCC) analysis using immunoassays. Main effects demonstrated primarily small and non-significant associations between perceived stress and HCC with different intensities of PA. Similar findings were observed between individual-level resilience resources and PA intensities, with the exception of hope (i.e., positive association with vigorous PA and negative association with sitting), self-efficacy (i.e., positive association with vigorous PA), and resilience (i.e., positive association with walking). Although certain individual-level resilience resources were perceived as beneficial for PA and sedentary time, the moderating role of resilience resources was not supported by the findings. The direct and moderating effects between stress, PA and resilience resources require further testing using longitudinal designs in which stressful periods occur naturally (e.g., exams for students) or are experimentally manipulated.
\end{abstract}

Keywords: hair cortisol; psychological capital; hope; self-efficacy; optimism. 


\section{Stress, Physical Activity and Resilience Resources: Tests of Direct and Moderation Effects in Young Adults}

Stress is a common part of everyday life, with most people at some point exposed to events which may affect their mental or physical health (Cooper \& Quick, 2017). Stressors range from everyday hassles (e.g., financial worries) to life changing events (e.g., death of a loved one). Within the stress literature (e.g., Blascovich, 2008; Lazarus \& Folkman, 1984), stress is said to occur when individuals perceive events or situations in their environment as taxing or exceeding their available resources. Broadly speaking, resources are concepts that "either are centrally valued in their own right (e.g., self-esteem, close attachments, health, and inner peace) or act as a means to obtain centrally valued ends (e.g., money, social support, and credit)" (Hobfoll, 2002, p. 307). When individuals perceive that their resources exceed the perceived demands of a stressor, stress is appraised as a challenge, yet when demands outweigh resources stress is evaluated as a threat (Blascovich, 2008). Following an appraisal of threat, stress typically leads to physiological and/or psychological responses that can be maladaptive for one's functioning (Chrousos, 2009). The deleterious health outcomes of stress are well-established and encompass both psychological (e.g., depression, generalised anxiety disorder, post-traumatic stress disorder) and physiological consequences (e.g., cardiovascular disease, obesity, type 2 diabetes; Thoits, 2010).

When examining the physiological responses to stress, one of the most widely studied markers is associated with activation of the hypothalamic-pituitary-adrenal (HPA) axis, namely the release of cortisol in response to the perceived threat or challenge. The HPA is highly responsive to stimulation from external stressors with acute levels of reactivity allowing for beneficial adaptive responses, namely "fight or flight" (Gidlow, Randall, Gillman, Smith, \& Jones, 2016). However, dysregulation in secretion over longer periods and/or high levels of repeated reactivity are maladaptive and represent a serious issue for both 
psychological and psychological health (Short et al., 2016; Stalder et al., 2017). Therefore, measures of HPA activity and its secretion of steroid hormones, particularly cortisol, have become important physiological markers of stress (Fischer et al., 2017).

Cortisol levels have traditionally been determined from salivary, blood, and/or urine samples (Stalder \& Kirschbaum, 2012). Although well-established within the literature, a single assessment of these methods provides only a snapshot of acute circulating cortisol levels at the time of sampling (saliva and plasma), or in the case of urine cortisol secretion a 24 hour period (Dettenborn, Tietze, Kirschbaum, \& Stalder, 2012; Gerber et al., 2013a; Stalder \& Kirschbaum, 2012). This temporal dimension represents a problem when attempting to assess cortisol levels over longer periods because HPA activity is highly variable (Stalder et al., 2017). Furthermore, the aforementioned methods are affected by a number of factors including circadian rhythmicity, transient levels of stress at the time of sampling, and factors that take place before sampling such as smoking, alcohol, physical activity (PA), and food consumption (e.g., Gerber et al., 2013b; Gidlow Stalder \& Kirschbaum, 2012; Stalder et al. 2017). Thus, although these methods have utility for capturing acute reactivity of the HPA, their use in measuring long-term or chronic activity is limited (Stalder et al., 2017).

The analysis of hair cortisol concentration (HCC) can attenuate the methodological limitations of traditional methods (Gerber et al., 2013a; Short, et al., 2016; Stalder \& Kirschbaum, 2012). As human hair grows approximately 1 centimetre per month (Wenning, 2000), HCC provides a reliable retrospective measure of cumulative secretion for up to 6 months (Kirschbaum, Tietze, Skolunda, \& Dettenborn, 2009). Research has linked HCC to conditions that are known to alter HPA functioning, such as Cushing's syndrome (Chrousos, 2009; Gidlow, Randall, Gillman, Silk, \& Jones, 2015). There is also strong evidence of the overall validity of HCC (e.g., Short et al., 2016; Stalder \& Kirschbaum, 2012), including 
good test re-test reliability and high levels of intraindividual stability (Stalder et al., 2017). For these reasons, HCC has been used increasingly over the past decade to examine the effects of chronic stress on a broad range of health-related outcomes (e.g., Stalder et al., 2017), including PA (e.g., Gerber et al., 2013a) and sedentary behaviour (e.g., Teychenne, Olstad, Turner, Costigan, \& Ball, 2018).

The beneficial effects of PA on a wide range of positive health outcomes, both psychological and physical, are well-established within the literature (e.g., StultsKolehmainen \& Sinha, 2014). Despite the wealth of information on its numerous benefits, many individuals do not partake in regular or sufficient levels of PA to confer health benefits (Hallal et al., 2012). It is also important to consider sedentary time (i.e., seated or reclined posture with low energy expenditure; Tremblay et al., 2017) alongside PA because high levels of "sitting time" can co-exist with an active lifestyle (Healy et al., 2008) and have deleterious effects on health (Ekelund et al., 2018). Stress is one of the major considerations when it comes to understanding why people engage in little PA or perform none at all (Burg et al., 2017), with research typically examining the salubrious effects of PA on stress (e.g., Wipfli, Rethorst, \& Landers, 2008). However, a systematic review of 168 studies examining the association between stress and PA and sedentary behaviours (Stults-Kolehmainen \& Sinha, 2014) found a majority of the reviewed studies (72.8\%) identified a negative association between stress and PA, suggesting there may be an inverse association with stress negatively affecting one's PA. In the case of prospective studies $(n=55), 76.4 \%$ found stress to predict lower levels of PA and exercise or higher levels of sedentary behaviour. Thus, the stressors people face may act as a barrier to healthy behaviours (e.g., PA) and perpetuate unhealthy choices (e.g., sedentary activities) (Burg et al., 2017). Based upon the recent review, the effects of stress on PA do not appear to be universal and therefore further examination of possible moderators that may protect an individual from the deleterious 
effects of stress is required (Stults-Kolehmainen \& Sinha, 2014). This explanation is in line with a resilience framework in which resources are said to buffer the maladaptive effects of stress and adversity on human functioning (Luthar, Cicchetti, \& Becker, 2000; Masten, 2011). Thus, there is a need to examine resilience resources that may buffer the effects of stress on PA.

Over the past two decades, there has been a surge of research on psychological resilience (Bonanno, Romero, \& Klein, 2015). Although debate remains regarding a universally accepted definition of resilience (Fletcher \& Sarkar, 2013), we ascribe to the perspective which suggests that resilience encapsulates one's capacity to sustain or regain relatively stable, healthy levels of psychological and physical functioning despite exposure to significant stressors or adversities (Luthar et al., 2000; Masten, 2011; Windle, 2011). Central to this process of recovery or adjustment are protective factors that encompass personal (e.g., optimism), community (e.g., social support), and societal (e.g., health services) resources (Masten, 2011; Windle, 2011). A recent conceptual and methodological review of resilience measures (Pangallo, Zibarras, Lewis, \& Flaxman, 2015) informed our choice of resilience resources in the current study. The higher-order concept of psychological capital (Luthans, Youssef, \& Avolio, 2007) is comprised of measures of hope, self-efficacy, resilience (bounce back), and optimism, and received the highest psychometric rating amongst 17 resilience measures. In addition, these individual-level resilience resources are modifiable and therefore can be targeted via interventions (e.g., self-efficacy, Sheeran et al., 2016; optimism, LittmanOvadia \& Nir, 2014). Within the context of a stress framework, it is likely that some people may have access to these resources in greater quantity and/or quality and therefore be more "resilient" to the deleterious effects of stress. However, the supposition that these resources may interact with stress and PA has not yet been examined with respect to the effects of stress on PA. Conducting research on this issue could shed light on which resources may help 
individuals to better cope with the demands of life and retain PA levels during stressful periods.

In summary, the objective of this study was to examine the associations between perceived and objective measures of stress, individual-level resilience resources, and their interaction in predicting different intensities of self-reported PA and sedentary behaviour. Aligned with a resilience perspective (Luthar, Cicchetti, \& Becker, 2000; Masten, 2011), we expected resilience resources to buffer the effects of stress on PA, such that the negative association between stress and PA would be attenuated for individuals with higher levels of these resources. We focus on university students for two key reasons. First, tertiary studies can be a highly stressful period (e.g., Dixon \& Kurpius, 2008), where students face numerous stressors across personal (e.g., relationship difficulties), academic (e.g., coursework demands) and occupational (e.g., career aspirations) contexts (Hurst, Baranik, \& Daniel, 2012). The stressful nature of this developmental period is reflected in prevalence statistics reported in national surveys (e.g., $64.2 \%$ of university students report their academic experiences to be very or extremely stressful; Headspace, 2016). Secondly, during stressful periods it is important that students remain active, as $40-50 \%$ of students are physically inactive and spend up to eight hours a day completing sedentary activities such as studying and watching television (Deliens, Deforche, De Bourdeaudhuij, \& Clarys, 2015).

\section{Methods}

\section{Participants}

Given the unavailability of existing work to inform expectations regarding a true effect size, we sought a compromise between financial resources (for hair cortisol analysis) and the smallest effect size of interest to determine how much data to collect. Power analysis using G*Power 3.1.9.2 (Faul, Erdfelder, Lang, \& Buchner, 2007) indicated that 121 participants would be required to detect a small-to-moderate increase in variance explained 
by the addition of the two interaction terms to the regression equation ( 8 total predictors, 2 tested predictors, $80 \%$ power, $\left.f^{2}=.12, \alpha=.01\right)$. A convenience sample of 140 adults $(70.7 \%$ female) aged $18-49$ years (mean $\pm \mathrm{SD} ; 21.68 \pm 4.88$ ) was recruited from two universities in Australia. Eligibility criteria included being an undergraduate student, willingness to provide a hair sample, and sufficient hair length $(2 \mathrm{~cm})$ on the posterior vertex region of the head. Participants were excluded from the analyses if they had an existing medical condition or musculoskeletal injury preventing them taking part in regular PA $(\mathrm{n}=5)$, resulting in a final sample of 135 participants $(71.1 \%$ female) aged $18-49$ years (mean \pm SD; $21.71 \pm 4.94$ ).

\section{Procedure}

This study was approved by the Human Research Ethics Committee at the lead author's institution. Participants were recruited to the study by two methods: (i) online via a research participation pool, via which students enrolled in health science degrees can elect to participate in research in return for course credit or gift vouchers ( $\$ 10$ iTunes voucher); and (ii) face-to-face via researcher-delivered invitations provided at the start of lectures within courses where students learn about the importance of PA (e.g., exercise science, physiotherapy). Students who expressed an interest in the study attended a 30 minute laboratory session where they provided informed consent, completed a multi-section survey ${ }^{1}$ online via Qualtrics (Qualtrics LLC, Utah, USA) and provided a sample of hair. The hair sample was cut as close as possible to the scalp and taken from the posterior vertex region, as previously described (Sauve et al., 2007). Hair samples were cut to approximately $1.5 \mathrm{~cm}$ (minimum 30-50 mg), wrapped in aluminium foil with an elastic band closest to the root end, and stored at room temperature before being sent to a specialist laboratory for analysis (Stratech Scientific APAC, Sydney).

\footnotetext{
${ }^{1}$ Participants also completed measures of lifetime adversity, academic stressors, social support, proactive goal regulation, and mental toughness. These variables will be the focus of separate publications; any overlap will be acknowledged appropriately.
} 


\section{Measures}

Demographics. Participants self-reported the following demographic information: age, $\operatorname{sex}($ female $=0$, male $=1$ ), existing musculoskeletal injury, height and weight.

Perceived stress. The 10-item version of the Perceived Stress Scale (PSS; Cohen, Kamark, \& Mermelstein, 1983) was used to assess to the degree to which situations in an individual's life over the past month were perceived as stressful (e.g., "In the last month, how often have you felt confident in your ability to handle your personal problems?'). Items were assessed on a 5-point scale from 0 never to 4 very often. Past work with student samples has provided reliability and validity evidence of test scores obtained with the PSS (Shapiro, Brown, Thoresen, \& Plante, 2011).

Physical activity. Participants self-reported their PA over the past 7 days using the 7item short form of the International Physical Activity Questionnaire (IPAQ) (Booth, 2000). Six items assess the frequency (days per week) and duration (hours and minutes) of PA intensities (vigorous, moderate, and walking), with two items per intensity (e.g. "On how many days did you do vigorous physical activities like heavy lifting, digging, aerobics, or fast bicycling? How much time did you usually spend doing vigorous physical activities on one of those days?"). One question is also included as an indicator of sedentary behaviour ("During the last 7 days, how much time did you usually spend sitting on a weekday?"). Using guidelines for data processing, the total number of minutes of each PA intensity were calculated following recommendations from the IPAQ website (www.ipaq.ki.se). In the current study, the three PA intensities were analysed as minutes per week, and sitting time as a daily average. In line with data processing guidelines (www.ipaq.ki.se) participants who answered 'don't know' for an intensity were omitted from analyses for that intensity. The IPAQ is one of the most widely used PA questionnaires, and meta-analytic data of 21 studies 
including 152 effect sizes spanning five PA categories has provided reliability and validity evidence of IPAQ scores (Kim, Park, \& Kang, 2013).

Resilience resources. Participants completed established measures of the components which comprise the higher-order construct of psychological capital (Luthans et al., 2007) including hope, generalised self-efficacy, resilience, optimism, as well as a measure of adaptability. All scales were measured on a 7-point scale ranging from 1 strongly disagree to 7 strongly agree.

Adult hope scale (AHS) (Snyder et al., 1991). The AHS measures an individual's hope toward goals and consists of 12 items, including four fillers. Two factors are measured, each with four items. The pathway items reflect people's perceptions of their capability to overcome goal-related barriers to achieve their goals (e.g., "I can think of many ways to get out of a jam"), whereas the agency subscale captures motivation and goal-directed energy to utilise pathways to pursue goals (e.g., "I energetically pursue my goals"). In this study, the filler items were omitted to reduce participant burden. In the current study, the two subscale scores were combined to create a total hope score, with a higher score reflecting greater hope. The full scales scores, including filler items, have demonstrated reliability evidence for use within student samples (e.g., Feldman \& Kubota, 2015).

General self-efficacy scale (GSE) (Chen, Gully, \& Eden, 2001). The GSE is an 8item, unidimensional measure of an individual's belief in their ability to perform in a variety of differing situations (e.g., "I believe I can succeed at most any endeavour to which I set my mind”). Scores on the GSE are summative with larger scores indicating higher levels selfefficacy. Test scores on the GSE have demonstrated good internal consistency ( $\alpha$ between .86 and .90) and test-retest reliability evidence ( $r=.62$ to .66) (Chen et al., 2001) in a student sample. 
Life orientation test - revised (LOT-R) (Scheier, Carver, \& Bridges, 1994). The 10 item LOT-R is a measure of optimism (e.g., "In uncertain times, I usually expect the best") and pessimism (e.g., "I hardly ever expect things to go my way"), with each dimension assessed using three items (the remaining four are fillers and were omitted in this study). We created a composite score of hope by combining the optimism and pessimism items (first reversed scored), with higher scores reflecting greater optimism. This cumulative scoring method has been commonly utilised in previous research (e.g., Atienza, Stephens, \& Townsend, 2004; Feldman et al., 2015; Hinz et al., 2017). Scores on the full LOT-R, including filler items, have demonstrated good internal consistency within a student sample ( $\alpha$ between .7 and .8; Scheier et al., 1994) and test-retest reliability evidence (.58 to .79; Atienza et al., 2004) in a female sample $\left(\mathrm{M}_{\mathrm{age}}=43.7\right)$.

Brief resilience scale (BRS) (Smith et al., 2008). The BRS measures an individual's perception of their ability to bounce back from stress. The scale consists of six items with three positively worded (e.g., "I usually come through difficult times with little trouble) and three negatively worded (e.g., "I have a hard time making it through stressful events") statements. The three negatively worded items were reverse scored to give a total resilience score with a higher score reflecting increased levels of resilience. The BRS scores have demonstrated good internal consistency ( $\alpha$ between .8 and .91) and test-retest reliability evidence ( $r=.69$ after 1 month and $r=.62$ after 3 months) (Smith et al., 2008) across samples consisting of students and cardiac rehabilitation patients.

Adaptability Scale (Martin, Nejad, Colmar, \& Liem, 2012). This 9-item tool is a measure of psycho-behavioural adjustment in response to novelty and/or uncertainty (e.g., "I am able to revise the way I think about a new situation to help me through it"). A higher score on the scale indicates a greater level of adaptability. Validity and reliability evidence of 
the scale scores has been demonstrated in cross-sectional and longitudinal studies, within high school and university student samples (e.g., Martin et al., 2012; 2013).

Hair cortisol. For preparation and cleaning, hair was cut to $1.5 \mathrm{~cm}$ from root end to represent cortisol secretion over a period of at least the previous month, due to the variability of hair growth rate (Wennig, 2000). Cortisol extraction followed the widely published ELISA method (e.g. Davenport, Tiefenbacher, Lutz, Novak, \& Meyer, 2006). Samples were first treated with isopropanol and then methanol, and allowed to dry for 5 days. In preparation for analysis, the hair was weighed for extraction and mechanically crushed. Methanol was used for extraction for 24 hours with sonication, with the tubes subsequently dried to remove all methanol before the samples were reconstituted in PBS for analysis. Cortisol was then analysed in duplicate using a commercially available ELISA immunoassay (Salimetrics, USA) according to the manufacturer's instructions (intra-assay variability $=5.4 \%$, inter-assay variability $=6 \%)$.

\section{Statistical Analyses}

Descriptive statistics were calculated using SPSS version 24 (SPSS Inc., Chicago, Illinois, USA). Linear regression was employed to examine the primary research questions. With regard to moderation effects, variables were grand mean centred prior to interaction terms being computed between each of the resilience resources and both subjective and objective measures of stress. Five potential individual-level resilience resources were tested (resilience, hope, optimism, self-efficacy, and adaptability) for each of four PA intensities (vigorous, moderate, walking, and sitting). Each moderator variable was examined separately against each of the PA intensities. The analysis was completed in a sequential stepwise fashion to examine the effects of the covariates (age, sex, and BMI) alone (step 1) and with the inclusion of direct effects of the stress variables and resilience resources (step 2), followed by the addition of the interaction terms (step 3). We planned to probe significant 
interactions using a simple slopes analysis (Aiken \& West, 1991). Hair cortisol concentrations were log-transformed so as to approximate a normal distribution, which is common in research utilising hair cortisol (e.g., Gerber et al., 2013a; Gidlow et al., 2015; Staufenbiel, Penninx, de Rijke, van den Akker, \& van Rossum, 2015). Due to the nature of the analysis and concerns relating to type I errors, we adopted a conservative level of statistical significance at $p<0.01$ to minimise the chances of a possible type I error whilst not choosing a level which was so stringent so as to risk the chance of a type II error. The moderation analyses were performed with Mplus 8 (Muthén \& Muthén, 2017) using a robust maximum likelihood estimator (MLR).

\section{Results}

\section{Descriptive Statistics and Bivariate Correlations}

Subscale level statistics including means, standard deviations, internal reliability estimates and bivariate correlations are presented in Table 1. Briefly, individual-level resilience resources demonstrated significant moderate to strong correlations with each other $(.43<r<.80)$, significant moderate to strong negative correlations with subjective stress $(-$ $.47<r<-.61)$, weak negative correlations with objective stress $(-.06<r<-.17)$, and weak to moderate correlations with PA $(.21<r<.32)$. The different intensities of PA demonstrated weak to moderate correlations with each other $(-.21<r<.32)$, a single significant weak negative correlation was observed between subjective stress and vigorous PA ( $r=-.23)$, and weak correlations were demonstrated between objective stress $(-.16<r<.03)$ and the different intensities of PA.

\section{Vigorous Physical Activity (VPA)}

Full details of the results for VPA are presented in Table 2; we focus here on statistically significant effects at step 3 of the analysis. Sex was positively associated with VPA across all models for each resilience resource, such that males reported higher levels of 
VPA. Conversely, age was negatively associated with VPA within the model for which bounce back resilience (BRS) was the individual-level resilience resource tested. In terms of resilience resources, hope and general self-efficacy evidenced moderate positive associations with VPA. There were no significant interaction effects for VPA.

\section{Moderate Physical Activity (MPA)}

Full details of the results for MPA are presented in Table 3. Sex was positively associated across all models for each resilience resource, such that males took part in higher levels of MPA. There were no other significant main or interaction effects for MPA.

\section{Walking}

Full details of the results for walking can be seen in Table 4. Age was negatively associated with walking in steps two and three of the bounce back resilience (BRS) model. Within this model, bounce back resilience (BRS) also demonstrated a moderate positive association with walking in steps two and three. There were no significant interaction effects for walking.

\section{Sitting}

Full details of the results for sitting are presented in Table 5. Age demonstrated a positive association with sitting time within step two of the models including hope, optimism and adaptability. There were no other significant main or interaction effects for sitting.

\section{Discussion}

In the current study we examined the moderating effects of individual-level resilience resources on the association between stress and PA among a sample of adults. Aligned with a stress-buffering hypothesis, we expected individual-level resilience resources (self-efficacy, hope, optimism, resilience, and adaptability) to moderate the effects of perceived and physiological stress on self-reported PA, such that individuals with higher levels of these resources would be less affected by the deleterious effects of stress and, therefore, report 
higher levels of PA. In terms of direct effects, bivariate correlations and regression coefficients indicated primarily small and non-significant negative associations between subjective and objective indices of stress and the different intensities of PA. The associations between individual-level resilience resources and PA intensities were mixed, though largely consistent across the bivariate correlations and regression coefficients in terms of magnitude and sign. Specifically, there were mainly significant small to moderate positive associations between individual-level resilience resources with VPA; small, non-significant positive associations with MPA and walking; and small, non-significant negative associations with sitting. Our predictions regarding the moderating effect of individual-level resilience resources were unsupported.

The small and primarily non-significant associations between perceived and physiological stress and PA have also been demonstrated in past research (e.g., Gidlow et al., 2015; Stalder et al., 2017). When examining the bivariate correlations, although they were primarily small and non-significant, the direction of the effects observed were mostly consistent with Stults-Kolehmainen and Sinha's (2014) review in that the majority of studies found a negative association, with higher levels of stress associated with lower levels of PA. Of the cross-sectional studies reviewed, $67 \%$ reported a negative association, with correlations within the small-moderate range $(-0.28$ to -0.42$)$. In the current study we sought to gain a more nuanced understanding of this association by examining different intensities of PA. We found a negative association for VPA and MPA, though not for walking, which may suggest that the association strengthens as PA intensity increases. Further support comes from the finding of a salient negative association between perceived stress and VPA which approached reported levels in the review paper. This finding suggests that the association between stress and PA is more important at the vigorous end of the PA spectrum, something that may have been hitherto overlooked due to amalgamated assessments of PA. Therefore, 
an interesting avenue for future research may be to explore the nature of the different intensities of PA that may be driving these associations with perceived stress.

Objectively measured stress displayed a similar trend to perceived stress whereby higher levels of HCC demonstrated small and non-significant associations with lower levels of PA. Previous research exploring this association is limited. For example, within StultsKolehmainen and Sinha's review, although there were studies recruiting objectively stressed populations (e.g., caregivers) only three utilised an objective measure of stress. Similar small and non-significant associations have also been reported in past cross-sectional research utilising HCC (e.g., Stalder et al., 2013; Steptoe, Easterlin, \& Kirschbaum, 2017), as well as cross-sectional research specifically utilising the IPAQ as a measure of PA (Gidlow et al., 2016; Staufenbiel et al., 2015). The small and non-significant correlations with HCC extended to all self-report measures, with the exception of the bounce back resilience (BRS). Inconsistencies have often been observed in the findings between self-reported and physiological measures, adding to a growing body of literature advocating a "lack of psychoendocrine covariance" (Staufenbiel, Penninx, Spijker, Elzinga, \& van Rossum, 2013, p. 1230). Specifically, with regard to perceived stress and HCC, small associations have been observed frequently (e.g., Gidlow et al., 2015; Gidlow et al., 2016) and confirmed in metaanalytic syntheses (Stalder et al., 2017; Staufenbiel et al., 2013). One explanation for these findings is the temporal component of the assessments. Many studies have looked at hair lengths of 2-3 cm, representing approximately 2-3 months of secretion, against self-reported stress (PSS) which assesses perceived stress over the previous month. We considered this temporal dimension of the assessment protocol so that perceived stress and HCC overlapped; however, consistent with past work, we revealed a small and non-significant association. A second explanation relates to the context in which studies have been conducted; that is, participants typically have been assessed during periods of relatively low stress levels thereby 
stress could have had minimal effects on longer term cortisol secretion (Stalder et al., 2017). Future research can address this methodological limitation by assessing participants longitudinally during naturally occurring or experimentally induced stressful periods (e.g. examination periods).

The direct effects between the individual-level resilience resources and PA intensities were mixed. Examination of the bivariate correlations shows the effects were generally positive in nature, suggesting higher levels of resilience resources are associated with higher levels of PA. These findings are in line with past research which has shown higher levels of these personal resources to be linked to higher levels of PA (e.g., hope, Gustafsson, Podlog, \& Davis, 2017; self-efficacy, Lewis, Williams, Frayeh, \& Marcus, 2016; optimism, Huffman et al. 2016; and resilience, Gerber, Jonsdottir, Lindwall, \& Ahlborg, 2014). This observation was especially evident for VPA which demonstrated significant small to moderate associations with all resources, with the exception of optimism. However, this trend did not extend to sitting for which we observed a negative association. Intuitively, individuals with higher levels of resources who are taking part in more PA may in turn be spending less time sitting. It is possible that having higher levels of these resources may allow individuals to gain the benefits of PA and negate the deleterious effects of too much sedentary time. Although these findings suggest that higher levels of perceived resources are associated with greater levels of different PA intensities, the cross-sectional nature of this study precludes us from ruling out the alternative explanation that higher levels of PA are associated with increased perceptions of available resilience resources. Longitudinal studies are needed to establish the importance of the perceived availability of these resources, which could inform resource focused interventions that help individuals maintain PA levels during stressful periods. 
Within the regression analyses three of the examined individual-level resilience resources were found to share salient associations with PA. First, when looking at VPA the resources of hope and self-efficacy were found to have salient positive weak to moderate associations. A possible mechanism by which hope demonstrated this positive association with VPA is via its two interactive components; pathway and agency. For example, individuals who have higher levels of hope may have an increased awareness of the various routes to be physically active (pathway), and the motivation to use these routes (agency). The finding that self-efficacy was also related positively with VPA is interesting as a central tenet of hope theory is that those who have higher levels of hope are instilled with an increased feeling of self-efficacy (Snyder, 2002), and therefore could reflect a by-product of their enhanced awareness of pathways to achieve their PA goals. Hope theory (Snyder, 2002) also suggests that hope is linked to one's motivation towards a goal, thus the observed association between higher levels of hope and increased VPA can be seen to be in line with motivation towards a goal of being physically active. Furthermore, the negative association between hope and sitting time approached significance, and less time sitting could also be seen to be in line with a goal of being more physically active. Second, one's ability to bounce back from stress, as measured by the BRS, was found to share a significant positive weak to moderate association with walking activities. Research utilising the BRS has demonstrated that groups of individuals who display resilience are more physically active than those who had low levels of resilience (Gerber et al., 2014). Specifically, in relation to light physical activity (e.g., walking, light gardening), those who engaged in light physical activity had reduced odds of being classed as highly burdened or stressed, i.e. lower levels in the BRS. Bearing in mind the cross-sectional nature of these data, these findings suggest that individuals who are well resourced to bounce back from adversity are better equipped to engage in higher amounts of walking activity. Research exploring this association between resilience and PA 
has mainly been focused at higher intensities of PA (Thogersen-Ntoumani et al., 2017), thus further work is needed to disentangle the association at all intensities of PA. Together, these findings are important as moderate to vigorous PA is the most important form of activity for individuals to improve their fitness, and gain its related health benefits (Garber et al., 2011), and sedentary behaviour (sitting time) has consistently been shown to be associated with numerous deleterious outcomes (ANPHA, 2014). Therefore, the findings that these individual-level resilience resources are related to increased levels of PA are important and may offer a fruitful line of further enquiry.

When examining the moderation effects of individual-level resilience resources our hypothesis that these resources would moderate the association between stress and PA was unsupported. There are several possible explanations for the non-significant moderation effects observed in the current study. First, our selection of individual-level resilience resources may have been insensitive to the primary outcomes; future research should consider resilience sources that are contextually tailored to the outcomes of interest (e.g., exercise selfefficacy). Second, the degree to which individual-level resilience resources attenuate the effects of stress on PA may be small, yet practically meaningful, in which case the current study was likely underpowered to detect such an effect. Third, against the backdrop of the transactional perspective of stress (Lazarus \& Folkman, 1984), our focus on secondary appraisals (i.e., perceptions of one's available resources to deal with stressors) in the absence of primary appraisals (i.e., interpretation of the stressor as a threat or challenge to personal functioning) could be considered a simplistic view of association between stress and PA. For example, individual-level resilience resources might moderate the effect of one's interpretations of the stressors, rather than the degree to which stress has been experienced. Finally, the cross-sectional nature of this study means we captured a static snapshot of the associations between stress, PA and individual-level resilience resources; the interactive 
effects among these variables may be dynamic in nature and therefore cannot be captured using a cross-sectional design. Despite its potential significance, previous research exploring possible moderators of the stress-PA association is limited. In a recent study examining the possible bi-directional association between stress and PA, moderation effects were also examined, including the resource of optimism; similarly to the current study no moderation effects were observed (Burg et al., 2017). The current study utilised a cross sectional design, whereas Burg et al. (2017) utilised only baseline measures of possible moderators; thus, future research may benefit from longitudinal designs with repeated assessments of participant's dispositional levels of individual-level resilience resources.

\section{Strengths and Limitations}

Notable strengths of this study were the assessment of stress via perceived and physiological indices, decomposition of PA into its different intensities rather than a global score, and consideration of stress-buffering individual-level resilience resources.

Nevertheless, four limitations should be considered when interpreting our findings. First, the findings are based on a sample of university students (predominantly female) who engaged in relatively high levels of PA; therefore, caution should be taken if generalising to other populations, particularly as the bias in the sample (e.g., wide age range, incentives) may have decreased the likelihood of finding significant associations. For example, the higher percentage of females was likely due to our eligibility criterion of sufficient hair length (2 $\mathrm{cm}$ ) on the posterior vertex region of the head. Relatedly, the largely healthy nature of our sample means that we observed relatively low levels of perceived stress, which affects longer-term cortisol secretion (Stalder et al., 2017). When compared with past investigations of HCC in student samples, for example, cortisol levels in the current study $(3.91 \pm 3.52$ pg/mg) were considerably lower than values in past research (e.g., $19.9 \pm 33.5$ pg/mg, Karlen et al., 2011). Nevertheless, levels were similar to previous studies utilising the same (ELISA) 
analysis within the same laboratory $(3.51 \pm 3.11 \mathrm{pg} / \mathrm{mg}$, Simmons et al., 2016). Furthermore, liquid chromatography-mass spectrometry is seen as the gold-standard in cortisol extraction techniques (Gerber et al., 2013a), and in a sample of healthy adults levels of HCC were roughly equivalent $($ median $=3.18$, range $=2.16-5.58 \mathrm{pg} / \mathrm{mg}$; Staufenbiel et al., 2015). Second, as there was a small amount of missing data on the dependent variables, some of the analyses were insufficiently powered to detect the smallest effect size of interest in this study. Third, we excluded an assessment of stress appraisals, which may have mediated our findings, as they have been found to predict salivary cortisol levels in research in the physical domain (Quested et al., 2011). Relatedly, we are unable rule out the potential effects of possible depressive symptoms or time availability to partake in PA outside of university demands because we did not collect this information (e.g., number of hours of un/paid work). Finally, the reliance on the IPAQ as a self-report assessment of PA levels. The IPAQ measures an individual's perceptions of the amount of PA they take part in at different intensity levels, and these perceptions of PA intensities (e.g., moderate and vigorous) may vary greatly between individuals. Perhaps most salient, people tend to over report their activity levels on the IPAQ when compared to an objective measure of PA (e.g., accelerometer) (Rääsk et al., 2017), thus future research may benefit from utilising objective measures of PA.

\section{Conclusion}

There are theoretical reasons (e.g., buffering hypothesis) and empirical evidence (e.g., Gerber et al., 2014) to support the prediction that resilience resources buffer the effects of stress on PA. However, the results of this study are contrary to these expectations in that we found non-significant interaction associations between self-reported individual-level resilience resources and stress (self-reported and assessed via HCC) on PA intensities. Nevertheless, we did find that certain resources correlate with more PA time and less sitting 
time. These associations were observed in relation to VPA, which is an important intensity at which to exercise to attain to gain improvements in fitness, and its related health benefits. We also found that all resilience resources were negatively associated with perceived stress, and in the case of the BRS with HCC, again adding support to the importance of these resources. In light of the significant burden stress has on mental and physical health globally, it is important that strategies, such as resilience resource development programs, are explored which may help mitigate this burden for individuals. However, additional research is required to disentangle the dynamic associations between individual-level resilience resources and PA intensities before definitive recommendations can be made regarding the nature of such interventions. 


\section{References}

Aiken, L. S., \& West, S.G. (1991). Multiple Regression: Testing and Interpreting Interactions. Newbury Park, CA: Sage.

Atienza, A. A., Stephens, M. A. P., \& Townsend, A. L. (2004). Role stressors as predictors of changes in womens' optimistic expectations. Personality and Individual Differences, 37, 471-484. doi: 10.1016/j.paid.2003.09.016

Australian National Preventive Health Agency. (2014). Obesity: Sedentary behaviours and health promoting a healthy Australia. Retrieved from: https://sydney.edu.au/medicine/research/units/boden/ANPHA\%20Sedentary\%20Beha viours\%20and\%20Health.pdf

Blascovich, J. (2008). Challenge and threat. In A. J. Elliot (Ed.), Handbook of Approach and Avoidance Motivation (pp. 431-445). New York: Psychology Press.

Bonanno, G. A., Romero, S. A., \& Klein, S. I. (2015). The temporal elements of psychological resilience: An integrative framework for the study of individuals, families, and communities. Psychological Inquiry, 26, 139-169. doi:

10.1080/1047840X.2015.992677

Booth, M. (2000). Assessment of physical activity: an international perspective. Research Quarterly for Exercise and Sport, 71, 114-120. doi: $10.1080 / 02701367.2000 .11082794$

Burg, M. M., Schwartz, J. E., Kronish, I. M., Diaz, K. M., Alcantara, C., Duer-Hefele, J., \& Davidson, K. W. (2017). Does Stress Result in You Exercising Less? Or Does Exercising Result in You Being Less Stressed? Or Is It Both? Testing the Bidirectional Stress-Exercise Association at the Group and Person ( $\mathrm{N}$ of 1) Level. Annals of Behavioral Medicine, 799-809. doi: 10.1007/s12160-017-9902-4

Chen, G., Gully, S. M., \& Eden, D. (2001). Validation of a new general self-efficacy scale. 
Organizational Research Methods, 4, 62-83. doi: 10.1177/109442810141004

Chrousos, G. P. (2009). Stress and disorders of the stress system. Nature Reviews Endocrinology, 5, 374-381. doi: 10.1038/nrendo.2009.106

Cohen, S., Kamarck, T., \& Mermelstein, R. (1983). A global measure of perceived stress. Journal of Health and Social Behavior, 385-396. doi: 10.2307/2136404

Cooper, C.L., \& Quick, J.C. (2017). The Handbook of Stress and Health: A Guide to Research and Practice. Hoboken, N.J: John Wiley \& Sons.

Davenport, M.D., Tiefenbacher, S., Lutz, C.K., Novak, M.A., \& Meyer, J.S. (2006). Analysis of endogenous cortisol concentrations in the hair of rhesus macaques. General and Comparative Endocrinology, 147, 255-261. doi: 10.1016/j.ygcen.2006.01.005

Deliens, T., Deforche, B., De Bourdeaudhuij, I., \& Clarys, P. (2015). Determinants of physical activity and sedentary behaviour in university students: a qualitative study using focus group discussions. BMC Public Health, 15, 201. doi: 10.1186/s12889$015-1553-4$

Dettenborn, L., Tietze, A., Kirschbaum, C., \& Stalder, T. (2012). The assessment of cortisol in human hair: Associations with sociodemographic variables and potential confounders. Stress, 15, 578-588. doi: 10.3109/10253890.2012.654479

Dixon, S. K., \& Kurpius, S. E. R. (2008). Depression and college stress among university undergraduates: Do mattering and self-esteem make a difference?. Journal of College Student Development, 49, 412-424. doi: https://doi.org/10.1353/csd.0.0024

Ekelund, U., Brown, W. J., Steene-Johannessen, J., Fagerland, M. W., Owen, N., Powell, K. E., ... \& Lee, I. M. (2018). Do the associations of sedentary behaviour with cardiovascular disease mortality and cancer mortality differ by physical activity level? A systematic review and harmonised meta-analysis of data from 850060 participants. British Journal of Sports Medicine, 1 - 9. doi: 10.1136/bjsports-2017-098963 
Faul, F., Erdfelder, E., Lang, A.-G., \& Buchner, A. (2007). G*Power 3: A flexible statistical power analysis program for the social, behavioural, and biomedical sciences. Behaviour Research Methods, 39, 175-191.

Feldman, D. B., \& Kubota, M. (2015). Hope, self-efficacy, optimism, and academic achievement: Distinguishing constructs and levels of specificity in predicting college grade-point average. Learning and Individual Differences, 37, 210-216. doi: 10.1016/j.lindif.2014.11.022

Fischer, S., Duncko, R., Hatch, S. L., Papadopoulos, A., Goodwin, L., Frissa, S., Hotopf, M., \& Cleare, A. J. (2017). Sociodemographic, lifestyle, and psychosocial determinants of hair cortisol in a South London community sample. Psychoneuroendocrinology, 76, 144-153. doi: 10.1016/j.psyneuen.2016.11.011

Fletcher, D., \& Sarkar, M. (2013). Psychological resilience: a review and critique of definitions, concepts, and theory. European Psychologist, 18, 12-23. doi: $10.1027 / 1016-9040 / \mathrm{a} 000124$

Garber, C.E., Blissmer, B., Deschenes, M.R., Franklin, B.A., Lamonte, M.J., Lee, I.M., Nieman, D.C., \& Swain, D.P. (2011). Quantity and quality of exercise for developing and maintaining cardiorespiratory, musculoskeletal, and neuromotor fitness in apparently healthy adults: guidance for prescribing exercise. Medicine \& Science in Sports \& Exercise, 43, 1334-1359. doi: 10.1249/MSS.0b013e318213fefb

Gerber, M., Brand, S., Lindwall, M., Elliot, C., Kalak, N., Herrmann, C., Puhse, U., Jonsdottir, I. H. (2012). Concerns regarding hair cortisol as a biomarker of chronic stress in exercise and sport science. Journal of Sports Science Medicine, 11, 571-581.

Gerber, M., Jonsdottir, I. H., Kalak, N., Elliot, C., Pühse, U., Holsboer-Trachsler, E., \& Brand, S. (2013a). Objectively assessed physical activity is associated with increased hair cortisol content in young adults. Stress, 16, 593-599. doi: 
$10.3109 / 10253890.2013 .823599$

Gerber, M., Kalak, N., Elliot, C., Holsboer-Trachsler, E., Pühse, U., \& Brand, S. (2013b). Both hair cortisol levels and perceived stress predict increased symptoms of depression: an exploratory study in young adults. Neuropsychobiology, 68, 100-109. doi: $10.1159 / 000351735$

Gerber, M., Jonsdottir, I. H., Lindwall, M., \& Ahlborg, G. (2014). Physical activity in employees with differing occupational stress and mental health profiles: a latent profile analysis. Psychology of Sport and Exercise, 15, 649-658. doi: 10.1016/j.psychsport.2014.07.012

Gidlow, C. J., Randall, J., Gillman, J., Silk, S., \& Jones, M. V. (2015). Hair cortisol and selfreported stress in healthy, working adults. Psychoneuroendocrinology, 63, 163-169. doi: 10.1016/j.psyneuen.2015.09.022

Gidlow, C. J., Randall, J., Gillman, J., Smith, G. R., \& Jones, M. V. (2016). Natural environments and chronic stress measured by hair cortisol. Landscape and Urban Planning, 148, 61-67. doi: 10.1016/j.landurbplan.2015.12.009

Gustafsson, H., Podlog, L., \& Davis, P. (2017). Hope and Athletic Performance. In S. J. Lopez (Ed.). The Oxford Handbook of Hope. Oxford, UK: Oxford University Press.

Hallal, P. C., Andersen, L. B., Bull, F. C., Guthold, R., Haskell, W., Ekelund, U., \& Lancet Physical Activity Series Working Group. (2012). Global physical activity levels: surveillance progress, pitfalls, and prospects. The Lancet, 380, 247-257. doi: 10.1016/ S0140-6736(12)60646-1

Headspace National Youth Mental Health Foundation. (2016). National tertiary student wellbeing survey. Retrieved from: https://headspace.org.au/assets/Uploads/headspaceNUS-Publication-Digital.pdf.

Healy, G. N., Dunstan, D. W., Salmon, J. O., Shaw, J. E., Zimmet, P. Z., \& Owen, N. (2008). 
Television time and continuous metabolic risk in physically active adults. Medicine and Science in Sports and Exercise, 40, 639-645. doi:

10.1249/MSS.0b013e3181607421

Hinz, A., Sander, C., Glaesmer, H., Brähler, E., Zenger, M., Hilbert, A., \& Kocalevent, R. D. (2017). Optimism and pessimism in the general population: Psychometric properties of the Life Orientation Test (LOT-R). International Journal of Clinical and Health Psychology, 17, 161-170. doi: 10.1016/j.ijchp.2017.02.003

Hobfoll, S. E. (2002). Social and psychological resources and adaptation. Review of General Psychology, 6, 307. doi: 10.1037//1089-2680.6.4.307

Huffman, J. C., Beale, E. E., Celano, C. M., Beach, S. R., Belcher, A. M., Moore, S. V., ... \& Januzzi, J. L. (2016). Effects of optimism and gratitude on physical activity, biomarkers, and readmissions after an acute coronary syndrome. Circulation:

Cardiovascular Quality and Outcomes, 9, 55-63. doi:

10.1161/CIRCOUTCOMES.115.002184

Hurst, C. S., Baranik, L. E., \& Daniel, F. (2012). College student stressors: A review of the qualitative research. Stress and Health, 29, 275-285. doi: 10.1002/smi.2465

Kim, Y., Park, I., \& Kang, M. (2013). Convergent validity of the international physical activity questionnaire (IPAQ): meta-analysis. Public Health Nutrition, 16, 440-452. doi: $10.1017 / \mathrm{S} 1368980012002996$

Kirschbaum, C., Tietze, A., Skoluda, N., \& Dettenborn, L. (2009). Hair as a retrospective calendar of cortisol production-increased cortisol incorporation into hair in the third trimester of pregnancy. Psychoneuroendocrinology, 34, 32-37. doi: 10.1016/j.psyneuen.2008.08.024

Lazarus, R. S., \& Folkman, S. (1984). Stress, Appraisal, and Coping. New York: Springer Publishing Company. 
Lewis, B. A., Williams, D. M., Frayeh, A., \& Marcus, B. H. (2016). Self-efficacy versus perceived enjoyment as predictors of physical activity behaviour. Psychology \& Health, 31, 456-469. doi: 10.1080/08870446.2015.1111372

Littman-Ovadia, H., \& Nir, D. (2014). Looking forward to tomorrow: The buffering effect of a daily optimism intervention. The Journal of Positive Psychology, 9, 122-136. doi: $10.1080 / 17439760.2013 .853202$

Luthar, S. S., Cicchetti, D., \& Becker, B. (2000). The construct of resilience: A critical evaluation and guidelines for future work. Child Development, 71, 543-562. doi: $10.1111 / 1467-8624.00164$

Luthans, F., Youssef, C. M., \& Avolio, B. J. (2007). Psychological capital: Developing the human competitive edge. New York, NY: Oxford University Press.

Martin, A. J., Nejad, H., Colmar, S., \& Liem, G. A. D. (2012). Adaptability: Conceptual and empirical perspectives on responses to change, novelty and uncertainty. Australian Journal of Guidance and Counselling, 22, 58-81. doi: 10.1017/jgc.2012.8

Martin, A.J., Nejad, H.G., Colmar, S., \& Liem, G.A.D. (2013). Adaptability: How students' responses to uncertainty and novelty predict their academic and non-academic outcomes. Journal of Educational Psychology, 105, 728-746. doi: 10.1037/a0032794.

Martínez-Ramos, E., Martín-Borràs, C., Trujillo, J. M., Giné-Garriga, M., Martín-Cantera, C., Solà-Gonfaus, M., ... \& Beltran, A. M. (2015). Prolonged sitting time: barriers, facilitators and views on change among primary healthcare patients who are overweight or moderately obese. PloS one, 10, e0125739. doi:10.1371/journal.pone.0125739

Masten, A. S. (2011). Resilience in children threatened by extreme adversity: Frameworks for research, practice, and translational synergy. Development and Psychopathology, 23, 493-506. doi: 10.1017/S0954579411000198 
Muthén, L. K., \& Muthén, B. O. (1998-2017). Mplus user's guide (8th ed.). Los Angeles, CA: Muthén \& Muthén.

Pangallo, A., Zibarras, L., Lewis, R., \& Flaxman, P. (2015). Resilience through the lens of interactionism: A systematic review. Psychological Assessment, 27, 1-20. doi: $10.1037 /$ pas0000024

Quested, E., Bosch, J.A., Burns, V.E., Cumming, J., Ntoumanis, N., \& Duda, J.L. (2011). Basic psychological need satisfaction, stress-related appraisals, and dancers' cortisol and anxiety responses. Journal of Sport and Exercise Psychology, 33, 828-846. doi: 10.1123/jsep.33.6.828

Rääsk, T., Mäestu, J., Lätt, E., Jürimäe, J., Jürimäe, T., Vainik, U., \& Konstabel, K. (2017). Comparison of IPAQ-SF and Two Other Physical Activity Questionnaires with Accelerometer in Adolescent Boys. PloS one, 12. doi: 10.1371/journal.pone.0169527

Robotham, D., \& Julian, C. (2006). Stress and the higher education student: a critical review of the literature. Journal of Further and Higher Education, 30, 107-117. doi: $10.1080 / 03098770600617513$

Sauvé, B., Koren, G., Walsh, G., Tokmakejian, S., \& Van Uum, S. H. (2007). Measurement of cortisol in human hair as a biomarker of systemic exposure. Clinical \& Investigative Medicine, 30(5), 183-191.

Scheier, M. F., Carver, C. S., \& Bridges, M. W. (1994). Distinguishing optimism from neuroticism (and trait anxiety, self-mastery, and self-esteem): a reevaluation of the Life Orientation Test. Journal of Personality and Social Psychology, 67, 1063-1078. doi: $10.1037 / 0022-3514.67 .6 .1063$

Scheier, M. F., Matthews, K. A., Owens, J. F., Magovern, G. J., Lefebvre, R. C., Abbott, R. A., \& Carver, C. S. (1989). Dispositional optimism and recovery from coronary artery bypass surgery: the beneficial effects on physical and psychological well-being. 
Journal of Personality and Social Psychology, 57, 1024 -1040. doi: 10.1037/00223514.57.6.1024

Shapiro, S. L., Brown, K. W., Thoresen, C., \& Plante, T. G. (2011). The moderation of mindfulness-based stress reduction effects by trait mindfulness: results from a randomized controlled trial. Journal of Clinical Psychology, 67, 267-277. doi: 10.1002/jclp.20761

Short, S. J., Stalder, T., Marceau, K., Entringer, S., Moog, N. K., Shirtcliff, E. A., ... \& Buss, C. (2016). Correspondence between hair cortisol concentrations and 30-day integrated daily salivary and weekly urinary cortisol measures. Psychoneuroendocrinology, 71, 12-18. doi: 10.1016/j.psyneuen.2016.05.007

Sheeran, P., Maki, A., Montanaro, E., Avishai-Yitshak, A., Bryan, A., Klein, W. M., ... \& Rothman, A. J. (2016). The impact of changing attitudes, norms, and self-efficacy on health-related intentions and behavior: A meta-analysis. Health Psychology, 35, 11781188.

Simmons, J. G., Badcock, P. B., Whittle, S. L., Byrne, M. L., Mundy, L., Patton, G. C., ... \& Allen, N. B. (2016). The lifetime experience of traumatic events is associated with hair cortisol concentrations in community-based children. Psychoneuroendocrinology, 63, 276-281. doi: 10.1016/j.psyneuen.2015.10.004

Smith, B. W., Dalen, J., Wiggins, K., Tooley, E., Christopher, P., \& Bernard, J. (2008). The brief resilience scale: Assessing the ability to bounce back. International Journal of Behavioral Medicine, 15, 194- 200. doi: 10.1080/10705500802222972

Snyder, C. R., Harris, C., Anderson, J. R., Holleran, S. A., Irving, L. M., Sigmon, S. T., ... \& Harney, P. (1991). The will and the ways: development and validation of an individual-differences measure of hope. Journal of Personality and Social Psychology, 60, 570-585. doi: 10.1037/0022-3514.60.4.570 
Snyder, C. R. (2002). Hope theory: Rainbows in the mind. Psychological Inquiry, 13, 249275. doi: 10.1207/S15327965PLI1304_01

Stalder, T., \& Kirschbaum, C. (2012). Analysis of cortisol in hair-state of the art and future directions. Brain, Behavior, and Immunity, 26, 1019-1029. doi: 10.1016/j.bbi.2012.02.002

Stalder, T., Kirschbaum, C., Alexander, N., Bornstein, S. R., Gao, W., Miller, R., ... \& Fischer, J. E. (2013). Cortisol in hair and the metabolic syndrome. The Journal of Clinical Endocrinology \& Metabolism, 98, 2573-2580. doi: 10.1210/jc.2013-1056

Stalder, T., Steudte-Schmiedgen, S., Alexander, N., Klucken, T., Vater, A., Wichmann, S., Kirschbaum, C., \& Miller, R. (2017). Stress-related and basic determinants of hair cortisol in humans: a meta-analysis. Psychoneuroendocrinology, 77, 261-274. doi: 10.1016/j.psyneuen.2016.12.017

Staufenbiel, S. M., Penninx, B. W., Spijker, A. T., Elzinga, B. M., \& van Rossum, E. F. (2013). Hair cortisol, stress exposure, and mental health in humans: a systematic review. Psychoneuroendocrinology, 38, 1220-1235. doi:

10.1016/j.psyneuen.2012.11.015

Staufenbiel, S. M., Penninx, B. W., de Rijke, Y. B., van den Akker, E. L., \& van Rossum, E. F. (2015). Determinants of hair cortisol and hair cortisone concentrations in adults. Psychoneuroendocrinology, 60, 182-194. doi: 10.1016/j.psyneuen.2015.06.011

Steptoe, A., Easterlin, E., \& Kirschbaum, C. (2017). Conscientiousness, hair cortisol concentration, and health behaviour in older men and women. Psychoneuroendocrinology, 86, 122-127. doi: 10.1016/j.psyneuen.2017.09.016

Stults-Kolehmainen, M. A., \& Sinha, R. (2014). The effects of stress on physical activity and exercise. Sports Medicine, 44, 81-121. doi: 10.1007/s40279-013-0090-5

Teychenne, M., Olstad, D. L., Turner, A. I., Costigan, S. A., \& Ball, K. (2018). Sedentary 
behaviour and hair cortisol amongst women living in socioeconomically disadvantaged neighbourhoods: A cross-sectional study. International Journal of Environmental Research and Public Health, 15, 586 - 593. doi: 10.3390/ijerph15040586.

Thogersen-Ntoumani, C., Black, J., Lindwall, M., Whittaker, A., \& Balanos, G. M. (2017). Presenteeism, stress resilience, and physical activity in older manual workers: a person-centred analysis. European Journal of Aging, 14, 385-396. doi: $10.1007 / \mathrm{s} 10433-017-0418-3$

Thoits, P. A. (2010). Stress and health major findings and policy implications. Journal of Health and Social Behavior, 51(1 supp), S41-S53. doi: 10.1177/0022146510383499

Tremblay, M. S., Aubert, S., Barnes, J. D., Saunders, T. J., Carson, V., Latimer-Cheung, A. E., ... \& Chinapaw, M. J. (2017). Sedentary behavior research network (SBRN) terminology consensus project process and outcome. International Journal of Behavioral Nutrition and Physical Activity, 14, 75. doi: 10.1186/s12966-017-0525-8

Wennig, R. (2000). Potential problems with the interpretation of hair analysis results. Forensic Science International, 107, 5-12. doi: 10.1016/S0379-0738(99)00146-2

Windle, G. (2011). What is resilience? A review and concept analysis. Reviews in Clinical Gerontology, 21, 152-169. doi: 10.1017/S0959259810000420

Wipfli, B. M., Rethorst, C. D., \& Landers, D. M. (2008). The anxiolytic effects of exercise: a meta-analysis of randomized trials and dose-response analysis. Journal of Sport and Exercise Psychology, 30, 392-410. doi: 10.1123/jsep.30.4.392 
Table 1

Descriptive Statistics, Internal Reliability Estimates and Bivariate Correlations Among Study Variables

\begin{tabular}{|c|c|c|c|c|c|c|c|c|c|c|c|c|c|c|c|c|c|c|c|}
\hline \multirow[t]{2}{*}{ Variables } & \multicolumn{5}{|c|}{ Descriptive Statistics } & \multicolumn{14}{|c|}{ Correlations } \\
\hline & $\mathrm{N}$ & Mean & SD & Skew & Kurtosis & 1 & 2 & 3 & 4 & 5 & 6 & 7 & 8 & 9 & 10 & 11 & 12 & 13 & 14 \\
\hline 1. Age & 135 & 21.71 & 4.94 & 3.02 & 10.89 & - & & & & & & & & & & & & & \\
\hline 2. Gender & 135 & - & - & - & - & -.06 & - & & & & & & & & & & & & \\
\hline 3. BMI a & 135 & 22.75 & 3.03 & 0.52 & -0.12 & $.20^{*}$ & .09 & - & & & & & & & & & & & \\
\hline $\begin{array}{l}\text { 4. Perceived } \\
\text { Stress }{ }^{b}\end{array}$ & 135 & 1.89 & 0.64 & 0.20 & 0.10 & -.16 & $-.22 *$ & -.02 & $(.88)$ & & & & & & & & & & \\
\hline 5. Hair Cortisol ${ }^{c}$ & 135 & 0.49 & 0.28 & 0.24 & 1.60 & .08 & $-.34 * *$ & .17 & .12 & - & & & & & & & & & \\
\hline 6. Vigorous PA d & 132 & 155.04 & 186.71 & 1.78 & 3.42 & -.12 & $.35^{* *}$ & .04 & $-.23 * *$ & -.16 & - & & & & & & & & \\
\hline 7. Moderate PA ${ }^{\mathrm{e}}$ & 130 & 142.27 & 208.14 & 2.72 & 8.62 & .05 & $.33^{* *}$ & .03 & -.14 & -.15 & $.32 * *$ & - & & & & & & & \\
\hline 8. Walking ${ }^{\mathrm{f}}$ & 111 & 264.82 & 271.81 & 1.86 & 3.62 & -.15 & $.25^{*}$ & .06 & .07 & -.14 & .09 & .11 & - & & & & & & \\
\hline 9. Sitting ${ }^{g}$ & 127 & 376.54 & 191.00 & 0.86 & 0.52 & .16 & -.14 & -.03 & .08 & .03 & $-.21 *$ & -.17 & .00 & - & & & & & \\
\hline 11. Hope ${ }^{\mathrm{h}}$ & 135 & 5.01 & 0.96 & -0.82 & 1.79 & .09 & .12 & .04 & $-.55 * *$ & -.06 & $.32 * *$ & .16 & -.00 & $-.21^{*}$ & $.59^{* *}$ & $(.87)$ & & & \\
\hline 12. Optimism ${ }^{\text {h }}$ & 135 & 4.60 & 1.04 & -0.35 & -0.29 & .14 & .08 & .01 & $-.50 * *$ & -.11 & .14 & .01 & .02 & -.08 & $.43^{* *}$ & $.60^{* *}$ & $(.78)$ & & \\
\hline 13. Self-Efficacy h & 135 & 5.10 & 1.01 & -1.22 & 2.69 & .08 & .16 & .05 & $-.47 * *$ & -.08 & $.29 * *$ & .11 & -.06 & -.11 & $.61 * *$ & $.80^{* *}$ & $.58 * *$ & $(.93)$ & \\
\hline 14. Adaptability ${ }^{\mathrm{h}}$ & 135 & 4.80 & 1.01 & -0.84 & 1.35 & .14 & $.29 * *$ & -.02 & $-.47 * *$ & -.15 & $.26^{* *}$ & .14 & .10 & -.17 & $.64 * *$ & $.74 * *$ & $.51^{* *}$ & $.74 * *$ & $(.92)$ \\
\hline
\end{tabular}

Note. $\mathrm{a}=\mathrm{BMI}$ scores in $\mathrm{kg} / \mathrm{m}^{2} ; \mathrm{b}=$ Range $0-4 ; \mathrm{c}=$ Hair cortisol concentrations in $\mathrm{pg} \cdot \mathrm{mg}^{-1}$ Log transformed; $\mathrm{d}=$ Vigorous physical activity minutes per week; e $=$ Moderate physical activity minutes per week; $\mathrm{f}=$ Walking minutes per week; $\mathrm{g}=$ Sitting minutes per day; $\mathrm{h}=$ Range $1-7 ; *=$ Correlation is significant at the 0.05 level $(2$-tailed); $* *$ $=$ Correlation is significant at the 0.01 level (2-tailed). 
Table 2

Vigorous Physical Activity 3 Step Regression Analyses

\begin{tabular}{|c|c|c|c|c|c|c|c|c|c|c|c|c|}
\hline & \multicolumn{4}{|c|}{$\begin{array}{c}\text { Step 1 } \\
\text { Observations: } 132\end{array}$} & \multicolumn{4}{|c|}{ Step 2} & \multicolumn{4}{|c|}{ Step 3} \\
\hline & $\beta$ & \multicolumn{2}{|c|}{$95 \% \mathrm{CI}$} & $p$ & $\beta$ & \multicolumn{2}{|c|}{$95 \% \mathrm{CI}$} & $p$ & $\beta$ & \multicolumn{2}{|c|}{$95 \%$ CI } & $p$ \\
\hline Age & -0.105 & -0.212 & 0.003 & 0.056 & -0.157 & -0.275 & -0.040 & 0.009 & -0.163 & -0.287 & -0.040 & 0.009 \\
\hline Sex & 0.338 & 0.182 & 0.495 & 0.000 & 0.243 & 0.064 & 0.422 & 0.008 & 0.241 & 0.058 & 0.425 & 0.010 \\
\hline BMI & 0.033 & -0.114 & 0.180 & 0.661 & 0.063 & -0.084 & 0.211 & 0.401 & 0.055 & -0.089 & 0.199 & 0.457 \\
\hline $\mathrm{PSS}^{\mathrm{a}}$ & & & & & -0.085 & -0.252 & 0.082 & 0.320 & -0.082 & -0.250 & 0.086 & 0.338 \\
\hline $\mathrm{HCC}^{\mathrm{b}}$ & & & & & -0.036 & -0.247 & 0.174 & 0.736 & -0.037 & -0.237 & 0.164 & 0.721 \\
\hline $\mathrm{BRS}^{\mathrm{c}}$ & & & & & 0.175 & -0.023 & 0.372 & 0.083 & 0.193 & -0.011 & 0.396 & 0.063 \\
\hline PSSxBRS & & & & & & & & & -0.077 & -0.210 & 0.056 & 0.258 \\
\hline HCCxBRS & \multirow{2}{*}{\multicolumn{4}{|c|}{0.132}} & & & & & 0.007 & -0.151 & 0.165 & 0.931 \\
\hline $\mathrm{R}^{2}$ & & & & & \multicolumn{4}{|c|}{0.181} & \multicolumn{4}{|c|}{0.186} \\
\hline Age & -0.105 & -0.212 & 0.003 & 0.056 & -0.136 & -0.247 & $\begin{array}{l}-0.024 \\
\end{array}$ & 0.017 & -0.113 & -0.233 & 0.008 & 0.068 \\
\hline Sex & 0.338 & 0.182 & 0.495 & 0.000 & 0.281 & 0.116 & 0.446 & 0.001 & 0.287 & 0.123 & 0.452 & 0.001 \\
\hline BMI & 0.033 & -0.114 & 0.180 & 0.661 & 0.040 & -0.107 & 0.187 & 0.590 & 0.020 & -0.122 & 0.163 & 0.780 \\
\hline PSS & & & & & -0.028 & -0.193 & 0.137 & 0.741 & -0.016 & -0.180 & 0.148 & 0.852 \\
\hline $\mathrm{HCC}$ & & & & & -0.039 & -0.250 & 0.171 & 0.714 & -0.048 & -0.251 & 0.156 & 0.645 \\
\hline $\mathrm{HOP}^{\mathrm{d}}$ & & & & & 0.272 & 0.105 & 0.438 & 0.001 & 0.340 & 0.147 & 0.532 & 0.001 \\
\hline PSSxHOP & & & & & & & & & -0.105 & -0.252 & 0.041 & 0.159 \\
\hline HCCxHOP & & & & & & & & & -0.128 & -0.279 & 0.023 & 0.097 \\
\hline $\mathrm{R}^{2}$ & \multicolumn{4}{|c|}{0.132} & \multicolumn{4}{|c|}{0.214} & \multicolumn{4}{|c|}{0.243} \\
\hline Age & -0.105 & -0.212 & 0.003 & 0.056 & -0.140 & -0.266 & -0.015 & 0.029 & -0.139 & -0.268 & -0.010 & 0.035 \\
\hline Sex & 0.338 & 0.182 & 0.495 & 0.000 & 0.284 & 0.108 & 0.461 & 0.002 & 0.291 & 0.114 & 0.468 & 0.001 \\
\hline BMI & 0.033 & -0.114 & 0.180 & 0.661 & 0.046 & -0.096 & 0.188 & 0.523 & 0.037 & -0.107 & 0.181 & 0.615 \\
\hline PSS & & & & & -0.153 & -0.309 & 0.004 & 0.056 & -0.156 & -0.309 & -0.002 & 0.047 \\
\hline $\mathrm{HCC}$ & & & & & -0.036 & -0.256 & 0.183 & 0.746 & -0.038 & -0.258 & 0.182 & 0.738 \\
\hline LOT $^{\mathrm{e}}$ & & & & & 0.053 & -0.115 & 0.220 & 0.538 & 0.048 & -0.115 & 0.212 & 0.562 \\
\hline PSSxLOT & & & & & & & & & -0.020 & -0.147 & 0.106 & 0.753 \\
\hline HCCxLOT & & & & & & & & & -0.049 & -0.240 & 0.141 & 0.613 \\
\hline $\mathrm{R}^{2}$ & \multicolumn{4}{|c|}{0.132} & \multicolumn{4}{|c|}{0.165} & \multicolumn{4}{|c|}{0.168} \\
\hline Age & -0.105 & -0.212 & 0.003 & 0.056 & -0.138 & -0.249 & -0.026 & 0.015 & -0.130 & -0.248 & -0.012 & 0.030 \\
\hline Sex & 0.338 & 0.182 & 0.495 & 0.000 & 0.270 & 0.099 & 0.442 & 0.002 & 0.252 & 0.080 & 0.424 & 0.004 \\
\hline BMI & 0.033 & -0.114 & 0.180 & 0.661 & 0.040 & -0.105 & 0.184 & 0.590 & 0.033 & -0.112 & 0.178 & 0.658 \\
\hline PSS & & & & & -0.081 & -0.244 & 0.082 & 0.332 & -0.085 & -0.249 & 0.079 & 0.311 \\
\hline $\mathrm{HCC}$ & & & & & -0.037 & -0.248 & 0.174 & 0.731 & -0.049 & -0.244 & 0.147 & 0.627 \\
\hline $\mathrm{GSE}^{\mathrm{f}}$ & & & & & 0.210 & 0.073 & 0.347 & 0.003 & 0.275 & 0.106 & 0.445 & 0.001 \\
\hline PSSxGSE & & & & & & & & & -0.125 & -0.299 & 0.050 & 0.163 \\
\hline HCCxGSE & & & & & & & & & -0.178 & -0.339 & -0.018 & 0.030 \\
\hline $\mathrm{R}^{2}$ & \multicolumn{4}{|c|}{0.132} & \multicolumn{4}{|c|}{0.197} & \multicolumn{4}{|c|}{0.247} \\
\hline Age & -0.105 & -0.212 & 0.003 & 0.056 & -0.153 & -0.276 & -0.031 & 0.014 & -0.151 & -0.284 & -0.017 & 0.027 \\
\hline Sex & 0.338 & 0.182 & 0.495 & 0.000 & 0.250 & 0.075 & 0.426 & 0.005 & 0.240 & 0.062 & 0.419 & 0.008 \\
\hline BMI & 0.033 & -0.114 & 0.180 & 0.661 & 0.056 & -0.086 & 0.198 & 0.439 & 0.056 & -0.087 & 0.199 & 0.441 \\
\hline PSS & & & & & -0.119 & -0.282 & 0.045 & 0.156 & -0.112 & -0.277 & 0.053 & 0.183 \\
\hline $\mathrm{HCC}$ & & & & & -0.036 & -0.250 & 0.178 & 0.742 & -0.031 & -0.238 & 0.177 & 0.772 \\
\hline $\mathrm{ADA}^{\mathrm{g}}$ & & & & & 0.148 & -0.007 & 0.303 & 0.061 & 0.175 & -0.019 & 0.368 & 0.076 \\
\hline PSSxADA & & & & & & & & & -0.017 & -0.140 & 0.107 & 0.790 \\
\hline HCCxADA & & & & & & & & & -0.098 & -0.273 & 0.077 & 0.274 \\
\hline $\mathrm{R}^{2}$ & \multicolumn{4}{|c|}{0.132} & & 0. & 179 & & & & 89 & \\
\hline
\end{tabular}

Note . $\mathrm{a}=$ Perceived Stress; $\mathrm{b}=$ Hair Cortisol Concentration; $\mathrm{c}=$ Brief Resilience Scale; $\mathrm{d}=$ Hope Scale; $\mathrm{e}=$ Life Orientation Test; $\mathrm{f}=$ General Self-Efficacy; $\mathrm{g}=$ Adaptability; Boldface indicates significance $(p<0.01)$. 
Table 3

Moderate Physical Activity 3 Step Regression Analyses

\begin{tabular}{|c|c|c|c|c|c|c|c|c|c|c|c|c|}
\hline & \multicolumn{4}{|c|}{$\begin{array}{c}\text { Step 1 } \\
\text { Observations: } 130 \\
\end{array}$} & \multicolumn{4}{|c|}{ Step 2} & \multicolumn{4}{|c|}{ Step 3} \\
\hline & $\beta$ & \multicolumn{2}{|c|}{$95 \% \mathrm{CI}$} & $p$ & $\beta$ & \multicolumn{2}{|c|}{$95 \% \mathrm{CI}$} & $p$ & $\beta$ & \multicolumn{2}{|c|}{$95 \% \mathrm{CI}$} & $p$ \\
\hline Age & 0.069 & -0.174 & 0.313 & 0.577 & 0.049 & -0.187 & 0.284 & 0.684 & 0.045 & -0.173 & 0.264 & 0.685 \\
\hline Sex & 0.339 & 0.190 & 0.488 & 0.000 & 0.288 & 0.113 & 0.462 & 0.001 & 0.291 & 0.113 & 0.469 & 0.001 \\
\hline BMI & -0.019 & -0.166 & 0.129 & 0.805 & 0.005 & -0.141 & 0.150 & 0.952 & 0.003 & -0.141 & 0.147 & 0.969 \\
\hline $\mathrm{PSS}^{\mathrm{a}}$ & & & & & -0.001 & -0.208 & 0.207 & 0.996 & 0.000 & -0.205 & 0.205 & 1.000 \\
\hline $\mathrm{HCC}^{\mathrm{b}}$ & & & & & -0.036 & -0.231 & 0.160 & 0.722 & -0.041 & -0.229 & 0.147 & 0.667 \\
\hline $\mathrm{BRS}^{\mathrm{c}}$ & & & & & 0.105 & -0.080 & 0.291 & 0.265 & 0.102 & -0.087 & 0.291 & 0.292 \\
\hline PSSxBRS & & & & & & & & & -0.001 & -0.121 & 0.120 & 0.989 \\
\hline HCCxBRS & \multirow{2}{*}{\multicolumn{4}{|c|}{0.116}} & & & & & 0.037 & -0.157 & 0.231 & 0.709 \\
\hline $\mathrm{R}^{2}$ & & & & & \multicolumn{4}{|c|}{0.127} & \multicolumn{4}{|c|}{0.128} \\
\hline Age & 0.069 & -0.174 & 0.313 & 0.577 & 0.063 & -0.172 & 0.298 & 0.599 & 0.063 & -0.154 & 0.279 & 0.571 \\
\hline Sex & 0.339 & 0.190 & 0.488 & 0.000 & 0.317 & 0.153 & 0.480 & 0.000 & 0.316 & 0.154 & 0.477 & 0.000 \\
\hline BMI & -0.019 & -0.166 & 0.129 & 0.805 & -0.018 & -0.171 & 0.135 & 0.819 & -0.023 & -0.174 & 0.129 & 0.769 \\
\hline PSS & & & & & 0.022 & -0.163 & 0.207 & 0.815 & 0.030 & -0.155 & 0.214 & 0.753 \\
\hline $\mathrm{HCC}$ & & & & & -0.035 & -0.231 & 0.161 & 0.729 & -0.041 & -0.234 & 0.153 & 0.680 \\
\hline $\mathrm{HOP}^{\mathrm{d}}$ & & & & & 0.137 & -0.031 & 0.305 & 0.111 & 0.181 & -0.017 & 0.378 & 0.073 \\
\hline PSSxHOP & & & & & & & & & -0.092 & -0.262 & 0.079 & 0.292 \\
\hline HCCxHOP & & & & & & & & & -0.007 & -0.192 & 0.178 & 0.941 \\
\hline $\mathrm{R}^{2}$ & \multicolumn{4}{|c|}{0.116} & \multicolumn{4}{|c|}{0.133} & \multicolumn{4}{|c|}{0.140} \\
\hline Age & 0.069 & -0.174 & 0.313 & 0.577 & 0.066 & -0.187 & 0.319 & 0.607 & 0.062 & -0.182 & 0.305 & 0.618 \\
\hline Sex & 0.339 & 0.190 & 0.488 & 0.000 & 0.302 & 0.137 & 0.467 & 0.000 & 0.301 & 0.136 & 0.467 & 0.000 \\
\hline BMI & -0.019 & -0.166 & 0.129 & 0.805 & -0.002 & -0.150 & 0.146 & 0.976 & 0.006 & -0.142 & 0.154 & 0.939 \\
\hline PSS & & & & & -0.099 & -0.289 & 0.091 & 0.309 & -0.085 & -0.280 & 0.110 & 0.394 \\
\hline $\mathrm{HCC}$ & & & & & -0.047 & -0.242 & 0.149 & 0.640 & -0.048 & -0.240 & 0.145 & 0.626 \\
\hline LOT $^{\mathrm{e}}$ & & & & & -0.079 & -0.259 & 0.101 & 0.391 & -0.066 & -0.244 & 0.111 & 0.463 \\
\hline PSSxLOT & & & & & & & & & -0.042 & -0.195 & 0.110 & 0.585 \\
\hline HCCxLOT & & & & & & & & & 0.071 & -0.124 & 0.266 & 0.475 \\
\hline $\mathrm{R}^{2}$ & \multicolumn{4}{|c|}{0.116} & \multicolumn{4}{|c|}{0.125} & \multicolumn{4}{|c|}{0.130} \\
\hline Age & 0.069 & -0.174 & 0.313 & 0.577 & 0.061 & -0.190 & 0.311 & 0.635 & 0.062 & -0.195 & 0.318 & 0.636 \\
\hline Sex & 0.339 & 0.190 & 0.488 & 0.000 & 0.310 & 0.144 & 0.476 & 0.000 & 0.300 & 0.129 & 0.472 & 0.001 \\
\hline BMI & -0.019 & -0.166 & 0.129 & 0.805 & -0.009 & -0.162 & 0.143 & 0.904 & -0.009 & -0.163 & 0.144 & 0.904 \\
\hline PSS & & & & & -0.039 & -0.205 & 0.127 & 0.645 & -0.042 & -0.214 & 0.129 & 0.629 \\
\hline $\mathrm{HCC}$ & & & & & -0.037 & -0.232 & 0.158 & 0.710 & -0.043 & -0.238 & 0.152 & 0.666 \\
\hline $\mathrm{GSE}^{\mathrm{f}}$ & & & & & 0.038 & -0.097 & 0.173 & 0.582 & 0.068 & -0.091 & 0.228 & 0.402 \\
\hline PSSxGSE & & & & & & & & & -0.060 & -0.219 & 0.100 & 0.463 \\
\hline HCCxGSE & & & & & & & & & -0.054 & -0.238 & 0.130 & 0.566 \\
\hline $\mathrm{R}^{2}$ & \multicolumn{4}{|c|}{0.116} & \multicolumn{4}{|c|}{0.121} & \multicolumn{4}{|c|}{0.128} \\
\hline Age & 0.069 & -0.174 & 0.313 & 0.577 & 0.059 & -0.188 & 0.306 & 0.639 & 0.059 & -0.183 & 0.300 & 0.634 \\
\hline Sex & 0.339 & 0.190 & 0.488 & 0.000 & 0.308 & 0.137 & 0.479 & 0.000 & 0.308 & 0.131 & 0.485 & 0.001 \\
\hline BMI & -0.019 & -0.166 & 0.129 & 0.805 & -0.006 & -0.155 & 0.142 & 0.936 & -0.006 & -0.156 & 0.143 & 0.936 \\
\hline PSS & & & & & -0.051 & -0.223 & 0.122 & 0.566 & -0.051 & -0.223 & 0.121 & 0.564 \\
\hline $\mathrm{HCC}$ & & & & & -0.037 & -0.233 & 0.158 & 0.708 & -0.037 & -0.231 & 0.156 & 0.705 \\
\hline $\mathrm{ADA}^{\mathrm{g}}$ & & & & & 0.015 & -0.123 & 0.153 & 0.834 & 0.015 & -0.157 & 0.187 & 0.866 \\
\hline PSSxADA & & & & & & & & & -0.001 & -0.128 & 0.126 & 0.983 \\
\hline HCCxADA & \multirow{2}{*}{\multicolumn{4}{|c|}{0.116}} & & & & & 0.003 & -0.185 & 0.191 & 0.974 \\
\hline $\mathrm{R}^{2}$ & & & & & & & 20 & & & & & \\
\hline
\end{tabular}

Note . $\mathrm{a}=$ Perceived Stress; $\mathrm{b}=$ Hair Cortisol Concentration; $\mathrm{c}=$ Brief Resilience Scale; $\mathrm{d}=$ Hope Scale; $\mathrm{e}=$ Life Orientation Test; $\mathrm{f}=$ General Self-Efficacy; $\mathrm{g}=$ Adaptability; Boldface indicates significance $(p<0.01)$. 
Table 4

Walking Activity 3 Step Regression Analyses

\begin{tabular}{|c|c|c|c|c|c|c|c|c|c|c|c|c|}
\hline & \multicolumn{4}{|c|}{$\begin{array}{c}\text { Step 1 } \\
\text { Observations: } 111\end{array}$} & \multicolumn{4}{|c|}{ Step 2} & \multicolumn{4}{|c|}{ Step 3} \\
\hline & $\beta$ & \multicolumn{2}{|c|}{$95 \%$ CI } & $p$ & $\beta$ & \multicolumn{2}{|c|}{$95 \% \mathrm{CI}$} & $p$ & $\beta$ & \multicolumn{2}{|c|}{$95 \% \mathrm{CI}$} & $p$ \\
\hline Age & -0.133 & -0.243 & -0.023 & 0.018 & -0.148 & -0.259 & $\begin{array}{l}-0.038 \\
\end{array}$ & 0.008 & -0.147 & -0.255 & -0.038 & 0.008 \\
\hline Sex & 0.226 & 0.022 & 0.429 & 0.030 & 0.146 & -0.056 & 0.348 & 0.157 & 0.138 & -0.070 & 0.346 & 0.193 \\
\hline BMI & 0.068 & -0.080 & 0.216 & 0.366 & 0.096 & -0.056 & 0.249 & 0.216 & 0.108 & -0.045 & 0.260 & 0.166 \\
\hline PSS $^{\mathrm{a}}$ & & & & & 0.253 & 0.015 & 0.491 & 0.037 & 0.256 & 0.019 & 0.494 & 0.034 \\
\hline $\mathrm{HCC}^{\mathrm{b}}$ & & & & & -0.084 & -0.222 & 0.054 & 0.232 & -0.088 & -0.229 & 0.054 & 0.226 \\
\hline $\mathrm{BRS}^{\mathrm{c}}$ & & & & & 0.282 & 0.084 & 0.481 & 0.005 & 0.266 & 0.075 & 0.456 & 0.006 \\
\hline PSSxBRS & & & & & & & & & 0.099 & -0.078 & 0.275 & 0.272 \\
\hline HCCxBRS & \multirow{2}{*}{\multicolumn{4}{|c|}{0.079}} & \multirow{2}{*}{\multicolumn{4}{|c|}{0.137}} & -0.028 & -0.157 & 0.100 & 0.665 \\
\hline $\mathrm{R}^{2}$ & & & & & & & & & \multicolumn{4}{|c|}{0.146} \\
\hline Age & -0.133 & -0.243 & -0.023 & 0.018 & -0.116 & -0.222 & -0.010 & 0.032 & -0.116 & -0.220 & -0.012 & 0.030 \\
\hline Sex & 0.226 & 0.022 & 0.429 & 0.030 & 0.211 & 0.001 & 0.421 & 0.049 & 0.210 & -0.002 & 0.423 & 0.052 \\
\hline BMI & 0.068 & -0.080 & 0.216 & 0.366 & 0.076 & -0.081 & 0.234 & 0.343 & 0.079 & -0.080 & 0.238 & 0.328 \\
\hline PSS & & & & & 0.100 & -0.115 & 0.316 & 0.361 & 0.097 & -0.117 & 0.311 & 0.374 \\
\hline $\mathrm{HCC}$ & & & & & -0.084 & -0.224 & 0.055 & 0.234 & 0.084 & -0.223 & 0.055 & 0.237 \\
\hline $\mathrm{HOP}^{\mathrm{d}}$ & & & & & 0.015 & -0.183 & 0.213 & 0.884 & -0.010 & -0.224 & 0.204 & 0.925 \\
\hline PSSxHOP & & & & & & & & & 0.056 & -0.128 & 0.239 & 0.553 \\
\hline HCCxHOP & \multirow{2}{*}{\multicolumn{4}{|c|}{0.079}} & \multirow{2}{*}{\multicolumn{4}{|c|}{0.092}} & -0.010 & -0.151 & 0.132 & 0.893 \\
\hline $\mathrm{R}^{2}$ & & & & & & & & & \multicolumn{4}{|c|}{0.094} \\
\hline Age & -0.133 & -0.243 & -0.023 & 0.018 & -0.122 & -0.227 & -0.016 & 0.024 & -0.115 & -0.219 & -0.011 & 0.031 \\
\hline Sex & 0.226 & 0.022 & 0.429 & 0.030 & 0.218 & 0.007 & 0.429 & 0.043 & 0.237 & 0.015 & 0.460 & 0.037 \\
\hline BMI & 0.068 & -0.080 & 0.216 & 0.366 & 0.077 & -0.080 & 0.234 & 0.335 & 0.060 & -0.092 & 0.212 & 0.441 \\
\hline PSS & & & & & 0.136 & -0.085 & 0.356 & 0.228 & 0.138 & -0.093 & 0.368 & 0.242 \\
\hline $\mathrm{HCC}$ & & & & & -0.074 & -0.214 & 0.065 & 0.296 & -0.084 & -0.234 & 0.065 & 0.269 \\
\hline LOT $^{\mathrm{e}}$ & & & & & 0.090 & -0.144 & 0.324 & 0.449 & 0.086 & -0.146 & 0.318 & 0.470 \\
\hline PSSxLOT & & & & & & & & & -0.079 & -0.309 & 0.151 & 0.501 \\
\hline HCCxLOT & & & & & & & & & -0.063 & -0.238 & 0.112 & 0.479 \\
\hline $\mathrm{R}^{2}$ & \multicolumn{4}{|c|}{0.079} & \multicolumn{4}{|c|}{0.098} & \multicolumn{4}{|c|}{0.110} \\
\hline Age & -0.133 & -0.243 & -0.023 & 0.018 & -0.116 & -0.224 & -0.008 & 0.035 & -0.114 & -0.226 & -0.001 & 0.047 \\
\hline Sex & 0.226 & 0.022 & 0.429 & 0.030 & 0.217 & 0.006 & 0.429 & 0.044 & 0.226 & 0.012 & 0.440 & 0.039 \\
\hline BMI & 0.068 & -0.080 & 0.216 & 0.366 & 0.083 & -0.072 & 0.237 & 0.295 & 0.078 & -0.081 & 0.236 & 0.336 \\
\hline PSS & & & & & 0.061 & -0.133 & 0.254 & 0.540 & 0.065 & -0.131 & 0.261 & 0.513 \\
\hline $\mathrm{HCC}$ & & & & & -0.087 & -0.227 & 0.054 & 0.226 & -0.080 & -0.222 & 0.062 & 0.269 \\
\hline $\mathrm{GSE}^{\mathrm{f}}$ & & & & & -0.069 & -0.267 & 0.129 & 0.494 & -0.051 & -0.264 & 0.163 & 0.642 \\
\hline PSSxGSE & & & & & & & & & -0.028 & -0.257 & 0.201 & 0.812 \\
\hline HCCxGSE & \multirow{2}{*}{\multicolumn{4}{|c|}{0.079}} & & & & & 0.080 & -0.072 & 0.231 & 0.303 \\
\hline $\mathrm{R}^{2}$ & & & & & \multicolumn{4}{|c|}{0.095} & \multicolumn{4}{|c|}{0.101} \\
\hline Age & -0.133 & -0.243 & -0.023 & 0.018 & -0.127 & -0.240 & -0.013 & 0.028 & -0.124 & -0.241 & -0.008 & 0.036 \\
\hline Sex & 0.226 & 0.022 & 0.429 & 0.030 & 0.184 & -0.043 & 0.412 & 0.113 & 0.196 & -0.037 & 0.430 & 0.100 \\
\hline BMI & 0.068 & -0.080 & 0.216 & 0.366 & 0.080 & -0.081 & 0.240 & 0.330 & 0.076 & -0.086 & 0.239 & 0.356 \\
\hline PSS & & & & & 0.139 & -0.078 & 0.355 & 0.209 & 0.131 & -0.085 & 0.347 & 0.234 \\
\hline $\mathrm{HCC}$ & & & & & -0.082 & -0.219 & 0.055 & 0.241 & -0.086 & -0.225 & 0.054 & 0.229 \\
\hline $\mathrm{ADA}^{\mathrm{g}}$ & & & & & 0.109 & -0.078 & 0.296 & 0.252 & 0.080 & -0.118 & 0.278 & 0.428 \\
\hline PSSxADA & & & & & & & & & 0.045 & -0.088 & 0.178 & 0.508 \\
\hline HCCxADA & & & & & & & & & 0.073 & -0.043 & 0.189 & 0.215 \\
\hline $\mathrm{R}^{2}$ & \multicolumn{4}{|c|}{0.079} & & & 100 & & & & 09 & \\
\hline
\end{tabular}

Note . $\mathrm{a}=$ Perceived Stress; $\mathrm{b}=$ Hair Cortisol Concentration; $\mathrm{c}=$ Brief Resilience Scale; $\mathrm{d}=$ Hope Scale; $\mathrm{e}=$ Life Orientation Test; $\mathrm{f}=$ General Self-Efficacy; $\mathrm{g}=$ Adaptability; Boldface indicates significance $(p<0.01)$. 
Table 5

Sitting Time 3 Step Regression Analyses

\begin{tabular}{|c|c|c|c|c|c|c|c|c|c|c|c|c|}
\hline & \multicolumn{4}{|c|}{$\begin{array}{c}\text { Step 1 } \\
\text { Observations: } 127\end{array}$} & \multicolumn{4}{|c|}{ Step 2} & \multicolumn{4}{|c|}{ Step 3} \\
\hline & $\beta$ & \multicolumn{2}{|c|}{$95 \% \mathrm{CI}$} & $p$ & $\beta$ & \multicolumn{2}{|c|}{$95 \% \mathrm{CI}$} & $p$ & $\beta$ & \multicolumn{2}{|c|}{$95 \% \mathrm{CI}$} & $p$ \\
\hline Age & 0.164 & 0.031 & 0.297 & 0.015 & 0.166 & 0.025 & 0.307 & 0.021 & 0.160 & 0.011 & 0.308 & 0.035 \\
\hline Sex & -0.124 & -0.304 & 0.057 & 0.180 & -0.143 & -0.342 & 0.056 & 0.160 & -0.135 & -0.332 & 0.063 & 0.181 \\
\hline BMI & -0.053 & -0.210 & 0.104 & 0.506 & -0.040 & -0.199 & 0.119 & 0.619 & -0.035 & -0.190 & 0.120 & 0.658 \\
\hline $\mathrm{PSS}^{\mathrm{a}}$ & & & & & 0.163 & -0.105 & 0.430 & 0.233 & 0.161 & -0.104 & 0.426 & 0.233 \\
\hline $\mathrm{HCC}^{\mathrm{b}}$ & & & & & -0.026 & -0.161 & 0.109 & 0.706 & -0.042 & -0.190 & 0.105 & 0.575 \\
\hline $\mathrm{BRS}^{\mathrm{c}}$ & & & & & 0.134 & -0.128 & 0.395 & 0.316 & 0.112 & -0.156 & 0.380 & 0.411 \\
\hline PSSxBRS & & & & & & & & & 0.053 & -0.095 & 0.200 & 0.485 \\
\hline HCCxBRS & \multirow{2}{*}{\multicolumn{4}{|c|}{0.045}} & & & & & 0.088 & -0.089 & 0.264 & 0.329 \\
\hline $\mathrm{R}^{2}$ & & & & & \multicolumn{4}{|c|}{0.063} & \multicolumn{4}{|c|}{0.074} \\
\hline Age & 0.164 & 0.031 & 0.297 & 0.015 & 0.181 & 0.049 & 0.313 & 0.007 & 0.172 & 0.036 & 0.308 & 0.013 \\
\hline Sex & -0.124 & -0.304 & 0.057 & 0.180 & -0.106 & -0.291 & 0.079 & 0.262 & -0.107 & -0.290 & 0.076 & 0.251 \\
\hline BMI & -0.053 & -0.210 & 0.104 & 0.506 & -0.045 & -0.200 & 0.110 & 0.569 & -0.041 & -0.199 & 0.116 & 0.608 \\
\hline PSS & & & & & -0.032 & -0.248 & 0.184 & 0.772 & -0.032 & -0.255 & 0.192 & 0.781 \\
\hline $\mathrm{HCC}$ & & & & & -0.029 & -0.163 & 0.104 & 0.666 & -0.028 & -0.163 & 0.107 & 0.685 \\
\hline HOP $^{d}$ & & & & & -0.223 & -0.404 & -0.043 & 0.015 & -0.226 & -0.446 & -0.006 & 0.044 \\
\hline PSSxHOP & & & & & & & & & -0.009 & -0.176 & 0.158 & 0.913 \\
\hline HCCxHOP & & & & & & & & & 0.042 & -0.091 & 0.175 & 0.533 \\
\hline $\mathrm{R}^{2}$ & \multicolumn{4}{|c|}{0.045} & \multicolumn{4}{|c|}{0.088} & \multicolumn{4}{|c|}{0.089} \\
\hline Age & 0.164 & 0.031 & 0.297 & 0.015 & 0.187 & 0.045 & 0.328 & 0.010 & 0.182 & 0.037 & 0.326 & 0.014 \\
\hline Sex & -0.124 & -0.304 & 0.057 & 0.180 & -0.115 & -0.303 & 0.073 & 0.231 & -0.109 & -0.295 & 0.078 & 0.253 \\
\hline BMI & -0.053 & -0.210 & 0.104 & 0.506 & -0.053 & -0.213 & 0.107 & 0.516 & -0.055 & -0.218 & 0.109 & 0.511 \\
\hline PSS & & & & & 0.057 & -0.138 & 0.252 & 0.566 & 0.087 & -0.120 & 0.294 & 0.412 \\
\hline $\mathrm{HCC}$ & & & & & -0.034 & -0.167 & 0.098 & 0.611 & -0.036 & -0.169 & 0.097 & 0.598 \\
\hline LOT $^{\mathrm{e}}$ & & & & & -0.070 & -0.235 & 0.095 & 0.407 & -0.050 & -0.218 & 0.118 & 0.559 \\
\hline PSSxLOT & & & & & & & & & -0.104 & -0.261 & 0.053 & 0.193 \\
\hline HCCxLOT & \multirow{2}{*}{\multicolumn{4}{|c|}{0.045}} & & & & & 0.071 & -0.078 & 0.220 & 0.348 \\
\hline $\mathrm{R}^{2}$ & & & & & \multicolumn{4}{|c|}{0.057} & \multicolumn{4}{|c|}{0.068} \\
\hline Age & 0.164 & 0.031 & 0.297 & 0.015 & 0.182 & 0.041 & 0.323 & 0.011 & 0.178 & 0.033 & 0.324 & 0.016 \\
\hline Sex & -0.124 & -0.304 & 0.057 & 0.180 & -0.107 & -0.296 & 0.082 & 0.267 & -0.104 & -0.291 & 0.084 & 0.278 \\
\hline BMI & -0.053 & -0.210 & 0.104 & 0.506 & -0.051 & -0.212 & 0.109 & 0.532 & -0.052 & -0.211 & 0.107 & 0.520 \\
\hline PSS & & & & & 0.053 & -0.161 & 0.267 & 0.628 & 0.063 & -0.151 & 0.277 & 0.564 \\
\hline $\mathrm{HCC}$ & & & & & -0.030 & -0.161 & 0.102 & 0.657 & -0.025 & -0.162 & 0.112 & 0.722 \\
\hline $\mathrm{GSE}^{\mathrm{f}}$ & & & & & -0.083 & -0.295 & 0.128 & 0.441 & -0.060 & -0.307 & 0.187 & 0.634 \\
\hline PSSxGSE & & & & & & & & & -0.051 & -0.236 & 0.133 & 0.586 \\
\hline HCCxGSE & & & & & & & & & 0.111 & -0.054 & 0.276 & 0.186 \\
\hline $\mathrm{R}^{2}$ & \multicolumn{4}{|c|}{0.045} & \multicolumn{4}{|c|}{0.058} & \multicolumn{4}{|c|}{0.071} \\
\hline Age & 0.164 & 0.031 & 0.297 & 0.015 & 0.199 & 0.057 & 0.341 & 0.006 & 0.180 & 0.034 & 0.327 & 0.016 \\
\hline Sex & -0.124 & -0.304 & 0.057 & 0.180 & -0.075 & -0.261 & 0.111 & 0.428 & -0.073 & -0.261 & 0.115 & 0.446 \\
\hline BMI & -0.053 & -0.210 & 0.104 & 0.506 & -0.066 & -0.227 & 0.096 & 0.426 & -0.066 & -0.224 & 0.092 & 0.414 \\
\hline PSS & & & & & 0.024 & -0.181 & 0.228 & 0.822 & 0.024 & -0.181 & 0.229 & 0.819 \\
\hline $\mathrm{HCC}$ & & & & & -0.036 & -0.165 & 0.093 & 0.588 & -0.033 & -0.160 & 0.094 & 0.608 \\
\hline ADA $^{g}$ & & & & & -0.166 & -0.365 & 0.032 & 0.101 & -0.137 & -0.376 & 0.102 & 0.261 \\
\hline PSSxADA & & & & & & & & & -0.102 & -0.314 & 0.109 & 0.343 \\
\hline HCCxADA & & & & & & & & & 0.095 & -0.044 & 0.234 & 0.179 \\
\hline $\mathrm{R}^{2}$ & \multicolumn{4}{|c|}{0.045} & & & 73 & & & & 86 & \\
\hline
\end{tabular}

Note a = Perceived Stress; $\mathrm{b}=$ Hair Cortisol Concentration; $\mathrm{c}=$ Brief Resilience Scale; $\mathrm{d}=$ Hope Scale; e = Life Orientation Test; $\mathrm{f}=$ General Self-Efficacy; $\mathrm{g}$ = Adaptability; Boldface indicates significance $(p<0.01)$. 
SUPPLEMENTARY MATERIAL

Stress, Physical Activity, and Resilience Resources: Tests of Direct and Moderation Effects in Young Adults

${ }^{*}$ Robin L. J. Lines ${ }^{1}$, Kagan J. Ducker ${ }^{1}$, Nikos Ntoumanis ${ }^{2}$, Cecilie Thøgersen-Ntoumani ${ }^{2}$, David Fletcher ${ }^{3}$, Sarah McGarry ${ }^{4}$, and Daniel F. Gucciardi ${ }^{1}$

${ }^{1}$ School of Physiotherapy and Exercise Science, Curtin University ${ }^{2}$ School of Psychology, Curtin University

${ }^{3}$ School of Sport, Exercise and Health Sciences, Loughborough University

${ }^{4}$ School of Occupational Therapy and Social Work, Curtin University 
Supplementary Table 1. Vigorous Physical Activity.

\begin{tabular}{|c|c|c|c|c|}
\hline & $\beta$ & \multicolumn{2}{|c|}{$95 \% \mathrm{CI}$} & $p$ \\
\hline Age & -0.140 & -0.254 & -0.026 & 0.016 \\
\hline Sex & 0.225 & 0.040 & 0.410 & 0.017 \\
\hline BMI & 0.023 & -0.136 & 0.182 & 0.776 \\
\hline $\mathrm{PSS}^{\mathrm{a}}$ & -0.029 & -0.196 & 0.138 & 0.736 \\
\hline $\mathrm{HCC}^{\mathrm{b}}$ & -0.125 & -0.291 & 0.041 & 0.140 \\
\hline $\mathrm{BRS}^{\mathrm{c}}$ & 0.113 & -0.139 & 0.365 & 0.378 \\
\hline HOPE & 0.317 & 0.017 & 0.616 & 0.038 \\
\hline $\mathrm{LOT}^{\mathrm{d}}$ & -0.149 & -0.313 & 0.015 & 0.074 \\
\hline $\mathrm{GSE}^{\mathrm{e}}$ & 0.081 & -0.178 & 0.340 & 0.538 \\
\hline $\mathrm{ADAP}^{\mathrm{f}}$ & -0.063 & -0.339 & 0.212 & 0.652 \\
\hline PSSxBRS & -0.110 & -0.336 & 0.117 & 0.342 \\
\hline HCCxBRS & 0.216 & 0.005 & 0.426 & 0.045 \\
\hline PSSxHOPE & -0.103 & -0.491 & 0.285 & 0.603 \\
\hline HCCXHOPE & 0.127 & -0.216 & 0.470 & 0.468 \\
\hline PSSxLOT & -0.026 & -0.180 & 0.127 & 0.735 \\
\hline HCCxLOT & 0.016 & -0.256 & 0.288 & 0.910 \\
\hline PSSxGSE & -0.218 & -0.527 & 0.090 & 0.166 \\
\hline HCCxGSE & -0.461 & -0.890 & -0.032 & 0.035 \\
\hline PSSxADAP & 0.317 & -0.039 & 0.673 & 0.081 \\
\hline HCCXADAP & -0.007 & -0.250 & 0.236 & 0.955 \\
\hline
\end{tabular}

Note. $\mathrm{a}=$ Perceived Stress; $\mathrm{b}=$ Hair Cortisol Concentration; $\mathrm{c}=$ Brief Resilience Scale; $\mathrm{d}=$ Life Orientation Test; e = General Self-Efficacy; $\mathrm{f}=$ Adaptability.

Supplementary Table 2. Moderate Physical Activity.

\begin{tabular}{|c|c|c|c|c|}
\hline & $\beta$ & \multicolumn{2}{|c|}{$95 \% \mathrm{CI}$} & $p$ \\
\hline Age & 0.062 & -0.140 & 0.263 & 0.548 \\
\hline Sex & 0.252 & 0.055 & 0.449 & 0.012 \\
\hline BMI & 0.026 & -0.132 & 0.183 & 0.749 \\
\hline $\mathrm{PSS}^{\mathrm{a}}$ & 0.008 & -0.217 & 0.233 & 0.945 \\
\hline $\mathrm{HCC}^{\mathrm{b}}$ & -0.121 & -0.288 & 0.046 & 0.157 \\
\hline $\mathrm{BRS}^{\mathrm{c}}$ & 0.111 & -0.102 & 0.324 & 0.307 \\
\hline HOPE & 0.307 & 0.010 & 0.605 & 0.043 \\
\hline LOT & -0.170 & -0.382 & 0.042 & 0.116 \\
\hline GSE & -0.085 & -0.310 & 0.139 & 0.456 \\
\hline ADAP & -0.070 & -0.318 & 0.178 & 0.579 \\
\hline PSSxBRS & 0.136 & -0.127 & 0.398 & 0.311 \\
\hline HCCxBRS & 0.101 & -0.105 & 0.306 & 0.336 \\
\hline PSSxHOPE & -0.339 & -0.807 & 0.129 & 0.156 \\
\hline HCCXHOPE & 0.114 & -0.172 & 0.401 & 0.433 \\
\hline PSSxLOT & -0.068 & -0.283 & 0.148 & 0.539 \\
\hline HCCxLOT & 0.128 & -0.156 & 0.412 & 0.377 \\
\hline PSSxGSE & -0.050 & -0.435 & 0.336 & 0.801 \\
\hline HCCxGSE & -0.337 & -0.715 & 0.041 & 0.081 \\
\hline PSSxADAP & 0.250 & -0.108 & 0.609 & 0.171 \\
\hline HCCXADAP & 0.017 & -0.245 & 0.279 & 0.898 \\
\hline
\end{tabular}

Note. $\mathrm{a}=$ Perceived Stress; $\mathrm{b}=$ Hair Cortisol Concentration; $\mathrm{c}=$ Brief Resilience Scale; $\mathrm{d}=$ Life Orientation Test; e = General Self-Efficacy; $\mathrm{f}=$ Adaptability. 
Supplementary Table 3. Walking Activity.

\begin{tabular}{ccccc}
\hline & $\beta$ & \multicolumn{2}{c}{$95 \%$ CI } & $p$ \\
\hline Age & -0.115 & -0.249 & 0.018 & 0.090 \\
Sex & 0.122 & -0.132 & 0.375 & 0.347 \\
BMI & 0.134 & -0.014 & 0.283 & 0.077 \\
PSS $^{\mathrm{a}}$ & 0.249 & 0.048 & 0.450 & 0.015 \\
HCC $^{\mathrm{b}}$ & -0.091 & -0.260 & 0.077 & 0.287 \\
BRS $^{\mathrm{c}}$ & 0.365 & 0.172 & 0.558 & 0.000 \\
HOPE & -0.062 & -0.337 & 0.212 & 0.655 \\
LOT & 0.153 & -0.111 & 0.416 & 0.256 \\
GSE & -0.312 & -0.661 & 0.037 & 0.080 \\
ADAP & 0.121 & -0.152 & 0.394 & 0.385 \\
PSSxBRS & 0.251 & -0.056 & 0.558 & 0.109 \\
HCCxBRS & -0.149 & -0.323 & 0.025 & 0.093 \\
PSSxHOPE & 0.224 & -0.260 & 0.708 & 0.365 \\
HCCxHOPE & -0.110 & -0.390 & 0.169 & 0.439 \\
PSSxLOT & -0.141 & -0.367 & 0.084 & 0.220 \\
HCCxLOT & -0.062 & -0.342 & 0.218 & 0.664 \\
PSSxGSE & -0.563 & -1.062 & -0.063 & 0.027 \\
HCCxGSE & 0.112 & -0.274 & 0.497 & 0.570 \\
PSSxADAP & 0.301 & -0.046 & 0.648 & 0.089 \\
HCCxADAP & 0.167 & -0.086 & 0.419 & 0.196 \\
\hline
\end{tabular}

Note. $\mathrm{a}=$ Perceived Stress; $\mathrm{b}=$ Hair Cortisol Concentration; $\mathrm{c}=$ Brief Resilience Scale; $\mathrm{d}=$ Life Orientation Test; $\mathrm{e}=$ General Self-Efficacy; $\mathrm{f}=$ Adaptability .

Supplementary Table 4. Sitting Activity.

\begin{tabular}{|c|c|c|c|c|}
\hline & $\beta$ & \multicolumn{2}{|c|}{$95 \% \mathrm{CI}$} & $p$ \\
\hline Age & 0.178 & 0.017 & 0.339 & 0.031 \\
\hline Sex & -0.106 & -0.288 & 0.077 & 0.256 \\
\hline BMI & -0.005 & -0.164 & 0.155 & 0.954 \\
\hline $\mathrm{PSS}^{\mathrm{a}}$ & 0.069 & -0.188 & 0.325 & 0.600 \\
\hline $\mathrm{HCC}^{\mathrm{b}}$ & -0.022 & -0.172 & 0.128 & 0.778 \\
\hline $\mathrm{BRS}^{\mathrm{c}}$ & 0.175 & -0.085 & 0.434 & 0.187 \\
\hline HOPE & -0.355 & -0.674 & -0.037 & 0.029 \\
\hline LOT & 0.039 & -0.184 & 0.263 & 0.730 \\
\hline GSE & 0.152 & -0.229 & 0.534 & 0.434 \\
\hline ADAP & -0.056 & -0.343 & 0.231 & 0.701 \\
\hline PSSxBRS & 0.365 & 0.009 & 0.720 & 0.044 \\
\hline HCCxBRS & 0.048 & -0.177 & 0.273 & 0.674 \\
\hline PSSxHOPE & -0.014 & -0.523 & 0.494 & 0.956 \\
\hline HCCXHOPE & -0.255 & -0.542 & 0.032 & 0.081 \\
\hline PSSxLOT & -0.088 & -0.268 & 0.092 & 0.339 \\
\hline HCCxLOT & 0.074 & -0.141 & 0.289 & 0.501 \\
\hline PSSxGSE & 0.070 & -0.381 & 0.521 & 0.760 \\
\hline HCCXGSE & 0.274 & -0.098 & 0.645 & 0.149 \\
\hline PSSxADAP & -0.337 & -0.767 & 0.094 & 0.125 \\
\hline HCCXADAP & 0.001 & -0.300 & 0.302 & 0.994 \\
\hline
\end{tabular}

Note. $\mathrm{a}=$ Perceived Stress; $\mathrm{b}=$ Hair Cortisol Concentration; $\mathrm{c}=$ Brief Resilience Scale; $\mathrm{d}=$ Life Orientation Test; e = General Self-Efficacy; $\mathrm{f}=$ Adaptability. 
Supplementary Table 5. Descriptive statistics for square root transformed PA.

\begin{tabular}{lccccc}
\hline & $\mathrm{N}$ & Mean & SD & Skew & Kurtosis \\
\hline Vigorous PA & 132 & 9.78 & 7.73 & .39 & -.53 \\
Moderate PA & 130 & 9.20 & 7.61 & .90 & .88 \\
Walking Activity & 111 & 14.40 & 7.61 & .73 & .36 \\
Sitting Time & 127 & 18.78 & 4.91 & .14 & .11 \\
\hline
\end{tabular}


Supplementary Table 6. Vigorous Physical Activity - comparison of original with transformed responses.

\begin{tabular}{|c|c|c|c|c|c|c|c|c|}
\hline & \multicolumn{4}{|c|}{ Step 3 Original } & \multicolumn{4}{|c|}{ Step 3 Transformed } \\
\hline & $\beta$ & \multicolumn{2}{|c|}{$95 \% \mathrm{CI}$} & $p$ & $\beta$ & \multicolumn{2}{|c|}{$95 \% \mathrm{CI}$} & $p$ \\
\hline Age & -0.163 & -0.287 & -0.040 & 0.009 & -0.164 & -0.308 & -0.020 & 0.025 \\
\hline Sex & 0.241 & 0.058 & 0.425 & 0.010 & 0.264 & 0.095 & 0.434 & 0.002 \\
\hline BMI & 0.055 & -0.089 & 0.199 & 0.457 & 0.063 & -0.089 & 0.216 & 0.417 \\
\hline $\mathrm{PSS}^{\mathrm{a}}$ & -0.082 & -0.250 & 0.086 & 0.338 & -0.030 & -0.204 & 0.143 & 0.732 \\
\hline $\mathrm{HCC}^{\mathrm{b}}$ & -0.037 & -0.237 & 0.164 & 0.721 & 0.009 & -0.178 & 0.197 & 0.921 \\
\hline $\mathrm{BRS}^{\mathrm{c}}$ & 0.193 & -0.011 & 0.396 & 0.063 & 0.245 & 0.030 & 0.460 & 0.026 \\
\hline PSSxBRS & -0.077 & -0.210 & 0.056 & 0.258 & -0.019 & -0.145 & 0.107 & 0.771 \\
\hline HCCXBRS & 0.007 & -0.151 & 0.165 & 0.931 & 0.041 & -0.115 & 0.196 & 0.606 \\
\hline $\mathrm{R}^{2}$ & \multicolumn{4}{|c|}{0.186} & \multicolumn{4}{|c|}{0.199} \\
\hline Age & -0.113 & -0.233 & 0.008 & 0.068 & -0.102 & -0.251 & 0.048 & 0.183 \\
\hline Sex & 0.287 & 0.123 & 0.452 & 0.001 & 0.321 & 0.170 & 0.473 & 0.000 \\
\hline BMI & 0.020 & -0.122 & 0.163 & 0.780 & 0.021 & -0.128 & 0.170 & 0.783 \\
\hline PSS & -0.016 & -0.180 & 0.148 & 0.852 & 0.009 & -0.162 & 0.181 & 0.914 \\
\hline $\mathrm{HCC}$ & -0.048 & -0.251 & 0.156 & 0.645 & 0.007 & -0.170 & 0.184 & 0.937 \\
\hline $\mathrm{HOP}^{\mathrm{d}}$ & 0.340 & 0.147 & 0.532 & 0.001 & 0.335 & 0.140 & 0.530 & 0.001 \\
\hline PSSxHOP & -0.105 & -0.252 & 0.041 & 0.159 & -0.020 & -0.141 & 0.100 & 0.740 \\
\hline HCCxHOP & -0.128 & -0.279 & 0.023 & 0.097 & -0.143 & -0.308 & 0.022 & 0.090 \\
\hline $\mathrm{R}^{2}$ & \multicolumn{4}{|c|}{0.243} & \multicolumn{4}{|c|}{0.248} \\
\hline Age & -0.139 & -0.268 & -0.010 & 0.035 & -0.131 & -0.288 & 0.026 & 0.102 \\
\hline Sex & 0.291 & 0.114 & 0.468 & 0.001 & 0.320 & 0.155 & 0.485 & 0.000 \\
\hline BMI & 0.037 & -0.107 & 0.181 & 0.615 & 0.035 & -0.115 & 0.185 & 0.648 \\
\hline PSS & -0.156 & -0.309 & -0.002 & 0.047 & -0.146 & -0.316 & 0.023 & 0.091 \\
\hline $\mathrm{HCC}$ & -0.038 & -0.258 & 0.182 & 0.738 & 0.015 & -0.186 & 0.215 & 0.884 \\
\hline LOT $^{\mathrm{e}}$ & 0.048 & -0.115 & 0.212 & 0.562 & 0.047 & -0.118 & 0.212 & 0.579 \\
\hline PSSxLOT & -0.020 & -0.147 & 0.106 & 0.753 & 0.028 & -0.106 & 0.162 & 0.683 \\
\hline HCCXLOT & -0.049 & -0.240 & 0.141 & 0.613 & -0.063 & -0.249 & 0.123 & 0.508 \\
\hline $\mathrm{R}^{2}$ & \multicolumn{4}{|c|}{0.168} & \multicolumn{4}{|c|}{0.170} \\
\hline Age & -0.130 & -0.248 & -0.012 & 0.030 & -0.125 & -0.264 & 0.013 & 0.077 \\
\hline Sex & 0.252 & 0.080 & 0.424 & 0.004 & 0.288 & 0.130 & 0.446 & 0.000 \\
\hline BMI & 0.033 & -0.112 & 0.178 & 0.658 & 0.030 & -0.119 & 0.178 & 0.693 \\
\hline PSS & -0.085 & -0.249 & 0.079 & 0.311 & -0.046 & -0.219 & 0.126 & 0.598 \\
\hline $\mathrm{HCC}$ & -0.049 & -0.244 & 0.147 & 0.627 & 0.006 & -0.170 & 0.181 & 0.950 \\
\hline $\mathrm{GSE}^{\mathrm{f}}$ & 0.275 & 0.106 & 0.445 & 0.001 & 0.300 & 0.127 & 0.474 & 0.001 \\
\hline PSSxGSE & -0.125 & -0.299 & 0.050 & 0.163 & -0.075 & -0.232 & 0.081 & 0.347 \\
\hline HCCXGSE & -0.178 & -0.339 & -0.018 & 0.030 & -0.151 & -0.310 & 0.007 & 0.061 \\
\hline $\mathrm{R}^{2}$ & \multicolumn{4}{|c|}{0.247} & \multicolumn{4}{|c|}{0.246} \\
\hline Age & -0.151 & -0.284 & -0.017 & 0.027 & -0.135 & -0.293 & 0.024 & 0.095 \\
\hline Sex & 0.240 & 0.062 & 0.419 & 0.008 & 0.276 & 0.107 & 0.446 & 0.001 \\
\hline BMI & 0.056 & -0.087 & 0.199 & 0.441 & 0.053 & -0.096 & 0.201 & 0.487 \\
\hline PSS & -0.112 & -0.277 & 0.053 & 0.183 & -0.093 & -0.257 & 0.072 & 0.268 \\
\hline $\mathrm{HCC}$ & -0.031 & -0.238 & 0.177 & 0.772 & 0.016 & -0.175 & 0.208 & 0.866 \\
\hline $\mathrm{ADA}^{\mathrm{g}}$ & 0.175 & -0.019 & 0.368 & 0.076 & 0.151 & -0.047 & 0.349 & 0.134 \\
\hline PSSxADA & -0.017 & -0.140 & 0.107 & 0.790 & 0.073 & -0.061 & 0.207 & 0.284 \\
\hline HCCxADA & -0.098 & -0.273 & 0.077 & 0.274 & -0.084 & -0.265 & 0.096 & 0.358 \\
\hline $\mathrm{R}^{2}$ & \multicolumn{4}{|c|}{0.189} & \multicolumn{4}{|c|}{0.193} \\
\hline
\end{tabular}

Note. $\mathrm{a}=$ Perceived Stress; $\mathrm{b}=$ Hair Cortisol Concentration; $\mathrm{c}=$ Brief Resilience Scale; $\mathrm{d}=$ Hope Scale; $\mathrm{e}=$ Life Orientation Test; $\mathrm{f}=$ General Self-Efficacy; $\mathrm{g}=$ Adaptability; Boldface indicates significance $(p<0.01)$. 
Supplementary Table 7. Moderate Physical Activity - comparison of original with transformed responses.

\begin{tabular}{|c|c|c|c|c|c|c|c|c|}
\hline \multicolumn{5}{|c|}{ Step 3 Original } & \multicolumn{4}{|c|}{ Step 3 Transformed } \\
\hline & $\beta$ & \multicolumn{2}{|c|}{$95 \%$ CI } & $p$ & $\beta$ & \multicolumn{2}{|c|}{$95 \% \mathrm{CI}$} & $p$ \\
\hline Age & 0.045 & -0.173 & 0.264 & 0.685 & -0.031 & -0.256 & 0.195 & 0.790 \\
\hline Sex & 0.291 & 0.113 & 0.469 & 0.001 & 0.346 & 0.175 & 0.517 & 0.000 \\
\hline BMI & 0.003 & -0.141 & 0.147 & 0.969 & 0.010 & -0.151 & 0.171 & 0.904 \\
\hline $\mathrm{PSS}^{\mathrm{a}}$ & 0.000 & -0.205 & 0.205 & 1.000 & -0.043 & -0.246 & 0.159 & 0.674 \\
\hline $\mathrm{HCC}^{\mathrm{b}}$ & -0.041 & -0.229 & 0.147 & 0.667 & 0.005 & -0.180 & 0.190 & 0.957 \\
\hline $\mathrm{BRS}^{\mathrm{c}}$ & 0.102 & -0.087 & 0.291 & 0.292 & 0.077 & -0.133 & 0.287 & 0.473 \\
\hline PSSxBRS & -0.001 & -0.121 & 0.120 & 0.989 & 0.020 & -0.114 & 0.155 & 0.768 \\
\hline HCCXBRS & 0.037 & -0.157 & 0.231 & 0.709 & 0.037 & -0.169 & 0.243 & 0.725 \\
\hline $\mathrm{R}^{2}$ & \multicolumn{4}{|c|}{0.128} & \multicolumn{4}{|c|}{0.157} \\
\hline Age & 0.063 & -0.154 & 0.279 & 0.571 & -0.006 & -0.232 & 0.220 & 0.958 \\
\hline Sex & 0.316 & 0.154 & 0.477 & 0.000 & 0.369 & 0.212 & 0.527 & 0.000 \\
\hline BMI & -0.023 & -0.174 & 0.129 & 0.769 & -0.020 & -0.184 & 0.145 & 0.816 \\
\hline PSS & 0.030 & -0.155 & 0.214 & 0.753 & 0.009 & -0.188 & 0.206 & 0.928 \\
\hline $\mathrm{HCC}$ & -0.041 & -0.234 & 0.153 & 0.680 & 0.008 & -0.177 & 0.193 & 0.931 \\
\hline $\mathrm{HOP}^{\mathrm{d}}$ & 0.181 & -0.017 & 0.378 & 0.073 & 0.194 & -0.017 & 0.405 & 0.071 \\
\hline PSSxHOP & -0.092 & -0.262 & 0.079 & 0.292 & -0.046 & -0.218 & 0.125 & 0.596 \\
\hline НCСхHOP & -0.007 & -0.192 & 0.178 & 0.941 & -0.054 & -0.254 & 0.145 & 0.592 \\
\hline $\mathrm{R}^{2}$ & \multicolumn{4}{|c|}{0.140} & \multicolumn{4}{|c|}{0.175} \\
\hline Age & 0.062 & -0.182 & 0.305 & 0.618 & -0.015 & -0.273 & 0.243 & 0.908 \\
\hline Sex & 0.301 & 0.136 & 0.467 & 0.000 & 0.357 & 0.199 & 0.515 & 0.000 \\
\hline BMI & 0.006 & -0.142 & 0.154 & 0.939 & 0.004 & -0.152 & 0.160 & 0.960 \\
\hline PSS & -0.085 & -0.280 & 0.110 & 0.394 & -0.134 & -0.339 & 0.071 & 0.199 \\
\hline $\mathrm{HCC}$ & -0.048 & -0.240 & 0.145 & 0.626 & -0.005 & -0.192 & 0.182 & 0.958 \\
\hline $\mathrm{LOT}^{\mathrm{e}}$ & -0.066 & -0.244 & 0.111 & 0.463 & -0.092 & -0.294 & 0.109 & 0.369 \\
\hline PSSxLOT & -0.042 & -0.195 & 0.110 & 0.585 & -0.070 & -0.236 & 0.095 & 0.404 \\
\hline HCCxLOT & 0.071 & -0.124 & 0.266 & 0.475 & 0.001 & -0.194 & 0.195 & 0.994 \\
\hline $\mathrm{R}^{2}$ & \multicolumn{4}{|c|}{0.130} & \multicolumn{4}{|c|}{0.163} \\
\hline Age & 0.062 & -0.195 & 0.318 & 0.636 & -0.017 & -0.281 & 0.248 & 0.903 \\
\hline Sex & 0.300 & 0.129 & 0.472 & 0.001 & 0.353 & 0.187 & 0.520 & 0.000 \\
\hline BMI & -0.009 & -0.163 & 0.144 & 0.904 & 0.000 & -0.164 & 0.165 & 0.997 \\
\hline PSS & -0.042 & -0.214 & 0.129 & 0.629 & -0.086 & -0.269 & 0.098 & 0.359 \\
\hline $\mathrm{HCC}$ & -0.043 & -0.238 & 0.152 & 0.666 & 0.003 & -0.181 & 0.188 & 0.971 \\
\hline $\mathrm{GSE}^{\mathrm{f}}$ & 0.068 & -0.091 & 0.228 & 0.402 & 0.025 & -0.158 & 0.208 & 0.787 \\
\hline PSSxGSE & -0.060 & -0.219 & 0.100 & 0.463 & -0.006 & -0.183 & 0.171 & 0.948 \\
\hline HCCxGSE & -0.054 & -0.238 & 0.130 & 0.566 & -0.085 & -0.267 & 0.096 & 0.357 \\
\hline $\mathrm{R}^{2}$ & \multicolumn{4}{|c|}{0.128} & \multicolumn{4}{|c|}{0.159} \\
\hline Age & 0.059 & -0.183 & 0.300 & 0.634 & -0.016 & -0.262 & 0.230 & 0.900 \\
\hline Sex & 0.308 & 0.131 & 0.485 & 0.001 & 0.360 & 0.191 & 0.529 & 0.000 \\
\hline BMI & -0.006 & -0.156 & 0.143 & 0.936 & 0.000 & -0.161 & 0.160 & 0.996 \\
\hline PSS & -0.051 & -0.223 & 0.121 & 0.564 & -0.083 & -0.262 & 0.096 & 0.364 \\
\hline $\mathrm{HCC}$ & -0.037 & -0.231 & 0.156 & 0.705 & 0.009 & -0.177 & 0.196 & 0.922 \\
\hline $\mathrm{ADA}^{\mathrm{g}}$ & 0.015 & -0.157 & 0.187 & 0.866 & 0.003 & -0.192 & 0.199 & 0.974 \\
\hline PSSxADA & -0.001 & -0.128 & 0.126 & 0.983 & 0.029 & -0.110 & 0.169 & 0.680 \\
\hline HCCxADA & 0.003 & -0.185 & 0.191 & 0.974 & -0.007 & -0.202 & 0.188 & 0.944 \\
\hline $\mathrm{R}^{2}$ & \multicolumn{4}{|c|}{0.120} & \multicolumn{4}{|c|}{0.152} \\
\hline
\end{tabular}

Note. $\mathrm{a}=$ Perceived Stress; $\mathrm{b}=$ Hair Cortisol Concentration; $\mathrm{c}=$ Brief Resilience Scale; $\mathrm{d}=$ Hope Scale; $\mathrm{e}=$ Life Orientation Test; $\mathrm{f}=$ General Self-Efficacy; $\mathrm{g}=$ Adaptability; Boldface indicates significance $(p<0.01)$. 
Supplementary Table 8. Walking Activity - comparison of original with transformed responses.

\begin{tabular}{|c|c|c|c|c|c|c|c|c|}
\hline & \multicolumn{4}{|c|}{ Step 3 Original } & \multicolumn{4}{|c|}{ Step 3 Transformed } \\
\hline & $\beta$ & \multicolumn{2}{|c|}{$95 \%$ CI } & $p$ & $\beta$ & \multicolumn{2}{|c|}{$95 \%$ CI } & $p$ \\
\hline Age & -0.147 & -0.255 & -0.038 & 0.008 & -0.227 & -0.366 & -0.088 & 0.001 \\
\hline Sex & 0.138 & -0.070 & 0.346 & 0.193 & 0.082 & -0.125 & 0.288 & 0.437 \\
\hline BMI & 0.108 & -0.045 & 0.260 & 0.166 & 0.103 & -0.054 & 0.261 & 0.198 \\
\hline $\mathrm{PSS}^{\mathrm{a}}$ & 0.256 & 0.019 & 0.494 & 0.034 & 0.218 & 0.000 & 0.436 & 0.050 \\
\hline $\mathrm{HCC}^{\mathrm{b}}$ & -0.088 & -0.229 & 0.054 & 0.226 & -0.105 & -0.252 & 0.042 & 0.161 \\
\hline $\mathrm{BRS}^{\mathrm{c}}$ & 0.266 & 0.075 & 0.456 & 0.006 & 0.259 & 0.055 & 0.464 & 0.013 \\
\hline PSSxBRS & 0.099 & -0.078 & 0.275 & 0.272 & 0.157 & -0.029 & 0.344 & 0.099 \\
\hline HCCXBRS & -0.028 & -0.157 & 0.100 & 0.665 & -0.052 & -0.197 & 0.093 & 0.480 \\
\hline $\mathrm{R}^{2}$ & \multicolumn{4}{|c|}{0.146} & \multicolumn{4}{|c|}{0.168} \\
\hline Age & -0.116 & -0.220 & -0.012 & 0.030 & -0.193 & -0.327 & -0.059 & 0.005 \\
\hline Sex & 0.210 & -0.002 & 0.423 & 0.052 & 0.157 & -0.052 & 0.367 & 0.141 \\
\hline BMI & 0.079 & -0.080 & 0.238 & 0.328 & 0.070 & -0.092 & 0.233 & 0.396 \\
\hline PSS & 0.097 & -0.117 & 0.311 & 0.374 & 0.064 & -0.141 & 0.268 & 0.540 \\
\hline $\mathrm{HCC}$ & 0.084 & -0.223 & 0.055 & 0.237 & -0.100 & -0.245 & 0.045 & 0.177 \\
\hline $\mathrm{HOP}^{\mathrm{d}}$ & -0.010 & -0.224 & 0.204 & 0.925 & -0.027 & -0.243 & 0.190 & 0.810 \\
\hline PSSxHOP & 0.056 & -0.128 & 0.239 & 0.553 & 0.161 & -0.052 & 0.374 & 0.138 \\
\hline HCCxHOP & -0.010 & -0.151 & 0.132 & 0.893 & -0.050 & -0.198 & 0.099 & 0.513 \\
\hline $\mathrm{R}^{2}$ & \multicolumn{4}{|c|}{0.094} & \multicolumn{4}{|c|}{0.120} \\
\hline Age & -0.115 & -0.219 & -0.011 & 0.031 & -0.198 & -0.328 & -0.068 & 0.003 \\
\hline Sex & 0.237 & 0.015 & 0.460 & 0.037 & 0.181 & -0.035 & 0.397 & 0.101 \\
\hline BMI & 0.060 & -0.092 & 0.212 & 0.441 & 0.045 & -0.111 & 0.200 & 0.573 \\
\hline PSS & 0.138 & -0.093 & 0.368 & 0.242 & 0.088 & -0.162 & 0.339 & 0.490 \\
\hline $\mathrm{HCC}$ & -0.084 & -0.234 & 0.065 & 0.269 & -0.111 & -0.269 & 0.047 & 0.168 \\
\hline LOT $^{\mathrm{e}}$ & 0.086 & -0.146 & 0.318 & 0.470 & 0.076 & -0.152 & 0.305 & 0.512 \\
\hline PSSxLOT & -0.079 & -0.309 & 0.151 & 0.501 & -0.032 & -0.245 & 0.182 & 0.771 \\
\hline HCCXLOT & -0.063 & -0.238 & 0.112 & 0.479 & -0.110 & -0.285 & 0.065 & 0.219 \\
\hline $\mathrm{R}^{2}$ & \multicolumn{4}{|c|}{0.110} & \multicolumn{4}{|c|}{0.118} \\
\hline Age & -0.114 & -0.226 & -0.001 & 0.047 & -0.199 & -0.351 & -0.047 & 0.010 \\
\hline Sex & 0.226 & 0.012 & 0.440 & 0.039 & 0.175 & -0.037 & 0.386 & 0.105 \\
\hline BMI & 0.078 & -0.081 & 0.236 & 0.336 & 0.069 & -0.097 & 0.235 & 0.417 \\
\hline PSS & 0.065 & -0.131 & 0.261 & 0.513 & 0.039 & -0.157 & 0.235 & 0.696 \\
\hline $\mathrm{HCC}$ & -0.080 & -0.222 & 0.062 & 0.269 & -0.099 & -0.251 & 0.052 & 0.199 \\
\hline $\mathrm{GSE}^{\mathrm{f}}$ & -0.051 & -0.264 & 0.163 & 0.642 & -0.058 & -0.272 & 0.155 & 0.591 \\
\hline PSSxGSE & -0.028 & -0.257 & 0.201 & 0.812 & 0.065 & -0.183 & 0.312 & 0.608 \\
\hline HCCXGSE & 0.080 & -0.072 & 0.231 & 0.303 & 0.056 & -0.096 & 0.207 & 0.470 \\
\hline $\mathrm{R}^{2}$ & \multicolumn{4}{|c|}{0.101} & \multicolumn{4}{|c|}{0.107} \\
\hline Age & -0.124 & -0.241 & -0.008 & 0.036 & -0.203 & -0.356 & -0.051 & 0.009 \\
\hline Sex & 0.196 & -0.037 & 0.430 & 0.100 & 0.133 & -0.092 & 0.359 & 0.247 \\
\hline BMI & 0.076 & -0.086 & 0.239 & 0.356 & 0.065 & -0.105 & 0.236 & 0.454 \\
\hline PSS & 0.131 & -0.085 & 0.347 & 0.234 & 0.110 & -0.096 & 0.317 & 0.293 \\
\hline $\mathrm{HCC}$ & -0.086 & -0.225 & 0.054 & 0.229 & -0.109 & -0.258 & 0.040 & 0.153 \\
\hline $\mathrm{ADA}^{\mathrm{g}}$ & 0.080 & -0.118 & 0.278 & 0.428 & 0.098 & -0.105 & 0.301 & 0.343 \\
\hline PSSxADA & 0.045 & -0.088 & 0.178 & 0.508 & 0.117 & -0.050 & 0.284 & 0.170 \\
\hline HCCXADA & 0.073 & -0.043 & 0.189 & 0.215 & 0.051 & -0.082 & 0.184 & 0.454 \\
\hline $\mathrm{R}^{2}$ & \multicolumn{4}{|c|}{0.109} & \multicolumn{4}{|c|}{0.132} \\
\hline
\end{tabular}

Note. $\mathrm{a}=$ Perceived Stress; $\mathrm{b}=$ Hair Cortisol Concentration; $\mathrm{c}=$ Brief Resilience Scale; $\mathrm{d}=$ Hope Scale; $\mathrm{e}=$ Life Orientation Test; $\mathrm{f}=$ General Self-Efficacy; $\mathrm{g}=$ Adaptability; Boldface indicates significance $(p<0.01)$. 
Supplementary Table 9. Sitting Time - comparison of original with transformed responses.

\begin{tabular}{|c|c|c|c|c|c|c|c|c|}
\hline & \multicolumn{4}{|c|}{ Step 3 Original } & \multicolumn{4}{|c|}{ Step 3 Transformed } \\
\hline & $\beta$ & \multicolumn{2}{|c|}{$95 \% \mathrm{CI}$} & $p$ & $\beta$ & \multicolumn{2}{|c|}{$95 \% \mathrm{CI}$} & $p$ \\
\hline Age & 0.160 & 0.011 & 0.308 & 0.035 & 0.146 & -0.002 & 0.294 & 0.053 \\
\hline Sex & -0.135 & -0.332 & 0.063 & 0.181 & -0.151 & -0.343 & 0.040 & 0.121 \\
\hline BMI & -0.035 & -0.190 & 0.120 & 0.658 & -0.026 & -0.179 & 0.127 & 0.737 \\
\hline $\mathrm{PSS}^{\mathrm{a}}$ & 0.161 & -0.104 & 0.426 & 0.233 & 0.164 & -0.087 & 0.416 & 0.200 \\
\hline $\mathrm{HCC}^{\mathrm{b}}$ & -0.042 & -0.190 & 0.105 & 0.575 & -0.025 & -0.173 & 0.123 & 0.742 \\
\hline $\mathrm{BRS}^{\mathrm{c}}$ & 0.112 & -0.156 & 0.380 & 0.411 & 0.145 & -0.121 & 0.410 & 0.287 \\
\hline PSSxBRS & 0.053 & -0.095 & 0.200 & 0.485 & 0.010 & -0.138 & 0.158 & 0.895 \\
\hline HCCXBRS & 0.088 & -0.089 & 0.264 & 0.329 & 0.092 & -0.088 & 0.272 & 0.316 \\
\hline $\mathrm{R}^{2}$ & \multicolumn{4}{|c|}{0.074} & \multicolumn{4}{|c|}{0.075} \\
\hline Age & 0.172 & 0.036 & 0.308 & 0.013 & 0.166 & 0.026 & 0.307 & 0.020 \\
\hline Sex & -0.107 & -0.290 & 0.076 & 0.251 & -0.121 & -0.301 & 0.060 & 0.190 \\
\hline BMI & -0.041 & -0.199 & 0.116 & 0.608 & -0.034 & -0.191 & 0.123 & 0.671 \\
\hline PSS & -0.032 & -0.255 & 0.192 & 0.781 & -0.021 & -0.242 & 0.200 & 0.850 \\
\hline $\mathrm{HCC}$ & -0.028 & -0.163 & 0.107 & 0.685 & -0.013 & -0.147 & 0.122 & 0.853 \\
\hline $\mathrm{HOP}^{\mathrm{d}}$ & -0.226 & -0.446 & -0.006 & 0.044 & -0.174 & -0.402 & 0.054 & 0.135 \\
\hline PSSxHOP & -0.009 & -0.176 & 0.158 & 0.913 & -0.041 & -0.213 & 0.131 & 0.637 \\
\hline HCCxHOP & 0.042 & -0.091 & 0.175 & 0.533 & 0.027 & -0.104 & 0.159 & 0.682 \\
\hline $\mathrm{R}^{2}$ & \multicolumn{4}{|c|}{0.089} & \multicolumn{4}{|c|}{0.079} \\
\hline Age & 0.182 & 0.037 & 0.326 & 0.014 & 0.173 & 0.030 & 0.317 & 0.018 \\
\hline Sex & -0.109 & -0.295 & 0.078 & 0.253 & -0.119 & -0.301 & 0.062 & 0.198 \\
\hline BMI & -0.055 & -0.218 & 0.109 & 0.511 & -0.044 & -0.205 & 0.118 & 0.595 \\
\hline PSS & 0.087 & -0.120 & 0.294 & 0.412 & 0.076 & -0.120 & 0.272 & 0.448 \\
\hline $\mathrm{HCC}$ & -0.036 & -0.169 & 0.097 & 0.598 & -0.019 & -0.153 & 0.114 & 0.778 \\
\hline LOT $^{\mathrm{e}}$ & -0.050 & -0.218 & 0.118 & 0.559 & -0.049 & -0.218 & 0.121 & 0.573 \\
\hline PSSxLOT & -0.104 & -0.261 & 0.053 & 0.193 & -0.109 & -0.256 & 0.037 & 0.144 \\
\hline HCCxLOT & 0.071 & -0.078 & 0.220 & 0.348 & 0.063 & -0.084 & 0.210 & 0.403 \\
\hline $\mathrm{R}^{2}$ & \multicolumn{4}{|c|}{0.068} & \multicolumn{4}{|c|}{0.068} \\
\hline Age & 0.178 & 0.033 & 0.324 & 0.016 & 0.170 & 0.026 & 0.314 & 0.021 \\
\hline Sex & -0.104 & -0.291 & 0.084 & 0.278 & -0.118 & -0.298 & 0.062 & 0.199 \\
\hline BMI & -0.052 & -0.211 & 0.107 & 0.520 & -0.041 & -0.197 & 0.115 & 0.606 \\
\hline PSS & 0.063 & -0.151 & 0.277 & 0.564 & 0.056 & -0.159 & 0.272 & 0.609 \\
\hline $\mathrm{HCC}$ & -0.025 & -0.162 & 0.112 & 0.722 & -0.008 & -0.147 & 0.130 & 0.907 \\
\hline $\mathrm{GSE}^{\mathrm{f}}$ & -0.060 & -0.307 & 0.187 & 0.634 & -0.036 & -0.308 & 0.235 & 0.793 \\
\hline PSSxGSE & -0.051 & -0.236 & 0.133 & 0.586 & -0.085 & -0.284 & 0.113 & 0.400 \\
\hline HCCXGSE & 0.111 & -0.054 & 0.276 & 0.186 & 0.117 & -0.050 & 0.285 & 0.170 \\
\hline $\mathrm{R}^{2}$ & \multicolumn{4}{|c|}{0.071} & \multicolumn{4}{|c|}{0.073} \\
\hline Age & 0.180 & 0.034 & 0.327 & 0.016 & 0.165 & 0.017 & 0.312 & 0.029 \\
\hline Sex & -0.073 & -0.261 & 0.115 & 0.446 & -0.092 & -0.271 & 0.087 & 0.316 \\
\hline BMI & -0.066 & -0.224 & 0.092 & 0.414 & -0.052 & -0.210 & 0.107 & 0.522 \\
\hline PSS & 0.024 & -0.181 & 0.229 & 0.819 & 0.022 & -0.188 & 0.232 & 0.836 \\
\hline $\mathrm{HCC}$ & -0.033 & -0.160 & 0.094 & 0.608 & -0.014 & -0.141 & 0.114 & 0.835 \\
\hline $\mathrm{ADA}^{\mathrm{g}}$ & -0.137 & -0.376 & 0.102 & 0.261 & -0.099 & -0.372 & 0.173 & 0.475 \\
\hline PSSxADA & -0.102 & -0.314 & 0.109 & 0.343 & -0.142 & -0.375 & 0.091 & 0.233 \\
\hline HCCXADA & 0.095 & -0.044 & 0.234 & 0.179 & 0.103 & -0.044 & 0.250 & 0.170 \\
\hline $\mathrm{R}^{2}$ & \multicolumn{4}{|c|}{0.086} & \multicolumn{4}{|c|}{0.089} \\
\hline
\end{tabular}

Note $. \mathrm{a}=$ Perceived Stress; $\mathrm{b}=$ Hair Cortisol Concentration; $\mathrm{c}=$ Brief Resilience Scale; $\mathrm{d}=$ Hope Scale; $\mathrm{e}=$ Life Orientation Test; $\mathrm{f}=$ General Self-Efficacy; $\mathrm{g}$ = Adaptability; Boldface indicates significance $(p<0.01)$. 